\title{
Development and impact of hooks of high droplet concentration on remote southeast Pacific stratocumulus
}

\author{
R. C. George, R. Wood, C. S. Bretherton, and G. Painter \\ University of Washington, Seattle, Washington, USA \\ Correspondence to: R. C. George (rheag@uw.edu)
}

Received: 19 December 2012 - Published in Atmos. Chem. Phys. Discuss.: 24 January 2013

Revised: 1 May 2013 - Accepted: 23 May 2013 - Published: 4 July 2013

\begin{abstract}
Over the southeastern Pacific (SEP), droplet concentration $\left(N_{\mathrm{d}}\right)$ in the typically unpolluted marine stratocumulus west of $80^{\circ} \mathrm{W}$ ( $>1000 \mathrm{~km}$ offshore) is periodically strongly enhanced in zonally elongated "hook"-shaped features that increase albedo. Here, we examine three hook events using the chemistry version of the Weather Research and Forecasting model (WRF-Chem) with $14 \mathrm{~km}$ horizontal resolution, satellite data, and aircraft data from the VAMOS Ocean-Cloud-Atmosphere-Land Study Regional Experiment (VOCALS-REx). A particularly strong hook yields insights into the development, decay, and radiative impact of these features. Hook development occurs with $N_{\mathrm{d}}$ increasing to polluted levels over the remote ocean primarily due to entrainment of cloud condensation nuclei $(\mathrm{CCN})$ from the lower free troposphere (FT). The feature advects northwestward until the FT CCN source is depleted, after which $N_{\mathrm{d}}$ decreases over a few days due to precipitation and dilution. The model suggests that the FT CCN source supplying the hook consists of high concentrations of small accumulation-mode aerosols that contribute a relatively small amount of aerosol mass to the MBL, in agreement with near-coast VOCALS measurements of polluted layers in the FT. The aerosol particles in this hook originate mainly from a pulse of offshore flow that transports Santiago-region $\left(33-35^{\circ} \mathrm{S}\right)$ emissions to the remote marine FT.

To provide pollution $\mathrm{CCN}$ that can sustain hooks, the FT transport of pollution plumes to the remote ocean requires strong, deep offshore flow. Such flow is favored by a trough approaching the South American coast and a southeastward shift of the climatological subtropical high-pressure system. The model simulations show precipitation suppression in the hook and a corresponding increase in liquid water path (LWP) compared with a simulation without anthropogenic
\end{abstract}

sources. LWP also increases as the hook evolves over time due to increasing stability and decreasing subsidence. WRFChem suggests that dimethyl sulfide (DMS) significantly influences the aerosol number and size distributions in a hook, but that hooks do not form without FT CCN. The Twomey effect contributes $\sim 50-70 \%$ of the albedo increase due to the presence of the hook, while secondary aerosol indirect effects and meteorological influences also contribute significantly.

The source of hook aerosols is difficult to determine with the available observations alone. The model provides further explanation of the factors influencing hook formation. Two other weaker hooks during VOCALS-REx are not as well simulated but are also associated with FT offshore flow near Santiago. Hooks demonstrate the importance of freetropospheric transport of aerosols in modulating the droplet concentration in the southeastern Pacific stratocumulus deck, and present a formidable challenge to simulate accurately in large-scale models.

\section{Introduction}

The transport of anthropogenic aerosol and precursors from continents to remote marine regions impacts cloud microphysical and radiative properties (e.g., Schwartz et al., 2002). Aerosol number concentration, size distribution, chemical composition (which influences hygroscopicity), mixing state, and environmental properties (such as relative humidity, vertical velocity, and supersaturation) determine how many aerosols activate as cloud droplets (Penner et al., 2001). Aerosols affect cloud microphysical properties (e.g., droplet number concentration, $N_{\mathrm{d}}$ ), and indirectly their radiative and 
macrophysical properties (liquid water path, LWP; cloud fraction, CF). The first aerosol indirect effect (AIE), or the Twomey effect (Twomey, 1974), describes the increase in cloud albedo due to increasing $N_{\mathrm{d}}$ and droplet surface area absent changes in cloud macrophysics. Secondary AIEs involving changes to cloud macrophysical properties can enhance or offset the first AIE (Ackerman et al., 2004; Lohmann and Feichter, 2005; Bretherton et al., 2007; Wood, 2007). Together, AIEs are the primary sources of uncertainty in the anthropogenic impact on the global radiative budget (Randall et al., 2007).

Anthropogenic aerosols and their gaseous precursors emitted from urban sources along the Chilean coastline advect over the stratocumulus-dominated southeast Pacific (SEP; $\sim 10-40^{\circ} \mathrm{S}, 70-90^{\circ} \mathrm{W}$, Huneeus et al., 2006; Spak et al., 2010; Allen et al., 2011; Saide et al., 2012). The microphysics of marine stratocumulus is susceptible to aerosols (Platnick and Twomey, 1994), and the clouds over the SEP forming in extremely clean air from the remote southern Pacific are particularly susceptible to aerosol increases. Mean low-level southeasterly flow induced by the subtropical high (on average centered near $30^{\circ} \mathrm{S}, 90^{\circ} \mathrm{W}$ ) encourages lower tropospheric transport of continental air over the SEP. Further, the Andes form a high barrier within $200 \mathrm{~km}$ of the coast that discourages eastward transport of Chilean emissions. The SEP is therefore a region of strong contrasts between clean and polluted airmasses and an excellent testbed for studying cloud-aerosol interactions. The Andes interact with synoptic-scale dynamics (through mechanisms such as diurnal pumping), leading to episodic outflow of continental boundary layer air into the marine free troposphere (FT; Spak et al., 2010; Rahn and Garreaud, 2010b; Allen et al., 2011; Toniazzo et al., 2011; Saide et al., 2012). Due to subsidence associated with the subtropical high (Klein and Hartmann, 1993) and increasing marine boundary layer (MBL) depth with distance from the coast (Bretherton et al., 2010), this continental air can be transported by winds moving to the northwest and may eventually intersect the marine inversion and be entrained into the MBL (Allen et al., 2011; Saide et al., 2012). Precursor gaseous species can affect aerosols through in-cloud processing, contribute to new aerosol formation through nucleation, or condense onto preexisting particles (Seinfeld and Pandis, 1998). Chilean anthropogenic emissions of sulfate, organic, and other primary and secondary aerosols as well as their gaseous precursors (such as $\mathrm{SO}_{2}$, which oxidizes to sulfate) originate mainly from industrial and urban sources, including copper mining and the Santiago metropolis (Tsapakis et al., 2002; Schüller et al., 2008). Santiago's emissions combined with transport restricted by topography causes this city to have one of the largest mass loadings of $\mathrm{PM}_{10}$ (aerosols smaller than $10 \mu \mathrm{m}$ ) in the world ( $>50 \mu \mathrm{g} \mathrm{m}^{-3}$ in 2006, Muñoz and Alcafuz, 2012). Thus, the dynamic conditions that allow air from this region to advect over the SEP may lead to strong AIEs.
Over the SEP, $N_{\mathrm{d}}$ estimates derived from MODIS satellite retrievals (George and Wood, 2010) show strong mean zonal gradients from the relatively "pristine" MBL west of $80^{\circ} \mathrm{W}$ to high concentrations near to the Chilean coast (Fig. 1a). The increase east of $75^{\circ} \mathrm{W}$ is associated with anthropogenic aerosols transported by two pathways: direct advection in the MBL from coastal sources, and episodic transport in the FT and entrainment into the MBL (Huneeus et al., 2006; Clarke et al., 2010a). FT sources of CCN are important in many locations (Clarke and Kapustin, 2010). The Lagrangian evolution of MBL aerosol properties in stratus regions is strongly influenced by the composition of the overlying FT air. When clean the FT serves to dilute the MBL (Clarke et al., 1996), and nucleation from convective cloud outflow and long range transport can provide sources of new particles introduced into the MBL via entrainment (Clarke et al., 1998; Wood et al., 2000; Clarke et al., 2013). Aerosol observations and analysis (Clarke et al., 2010a,b) revealed layers of pollution aerosol above cloud transport from South America in some cases. Active entrainment of pollution aerosol was observed at sizes effective as CCN in VOCALS stratus clouds (Clarke et al., 2010a,b) similar to previously documented influences from long-range transport of pollution and entrainment found over the North Pacific (Clarke et al., 2001).

Composites of MODIS $N_{\mathrm{d}}$ and derived reflected solar flux at the top of the atmosphere (George and Wood, 2010) are constructed for those days when mean $N_{\mathrm{d}}$ in the domain 19$21^{\circ} \mathrm{S}, 82-86^{\circ} \mathrm{W}$ is more than $87 \mathrm{~cm}^{-3}(1$ standard deviation above the climatological mean). This box is chosen to sample the region where $N_{\mathrm{d}}$ contributes most to albedo variance (see Fig. 5 in George and Wood, 2010). Comparing these increased offshore $N_{\mathrm{d}}$ composites (Fig. 1b) with the mean state (Fig. 1a) reveals a shift in the pattern of $N_{\mathrm{d}}$ not only within the compositing box (which, by construction, must occur) but over a broad region between the box and the coast. The hook-like shape of enhanced $N_{\mathrm{d}}$ extends southeastward from the compositing domain (Fig. 1b) and strongly enhances the albedo and the Twomey effect offshore (Fig. 1c vs. d). Around the compositing box, days with high $N_{\mathrm{d}}$ experience $25-40 \mathrm{~W} \mathrm{~m}^{-2}$ larger reflected solar flux than on average, and $10-20 \mathrm{~W} \mathrm{~m}^{-2}(\sim 40-50 \%)$ of this is due to the Twomey effect. The remote composites therefore demonstrate important microphysically driven albedo variability in an often pristine region. The non-Twomey component of the albedo increases may be caused by secondary AIEs and/or meteorological covariability with $N_{\mathrm{d}}$. This motivates our need to investigate the reasons for strong $N_{\mathrm{d}}$ variability over the remote SEP.

Instantaneous images over consecutive days showing $N_{\mathrm{d}}$ from the GOES satellite (Sect. 2.1) during periods of elevated offshore $N_{\mathrm{d}}$ typically show a narrow band of high $N_{\mathrm{d}}$ characterized by an east-west "hook" of high $N_{\mathrm{d}}$ with maximum $N_{\mathrm{d}}$ in the range $150-350 \mathrm{~cm}^{-3}$ standing out against marine background values of $\sim 50 \mathrm{~cm}^{-3}$. The example in Fig. 2 (17-20 October 2008) occurred during the VAMOS Ocean-Cloud-Atmosphere-Land Study Regional Experiment 


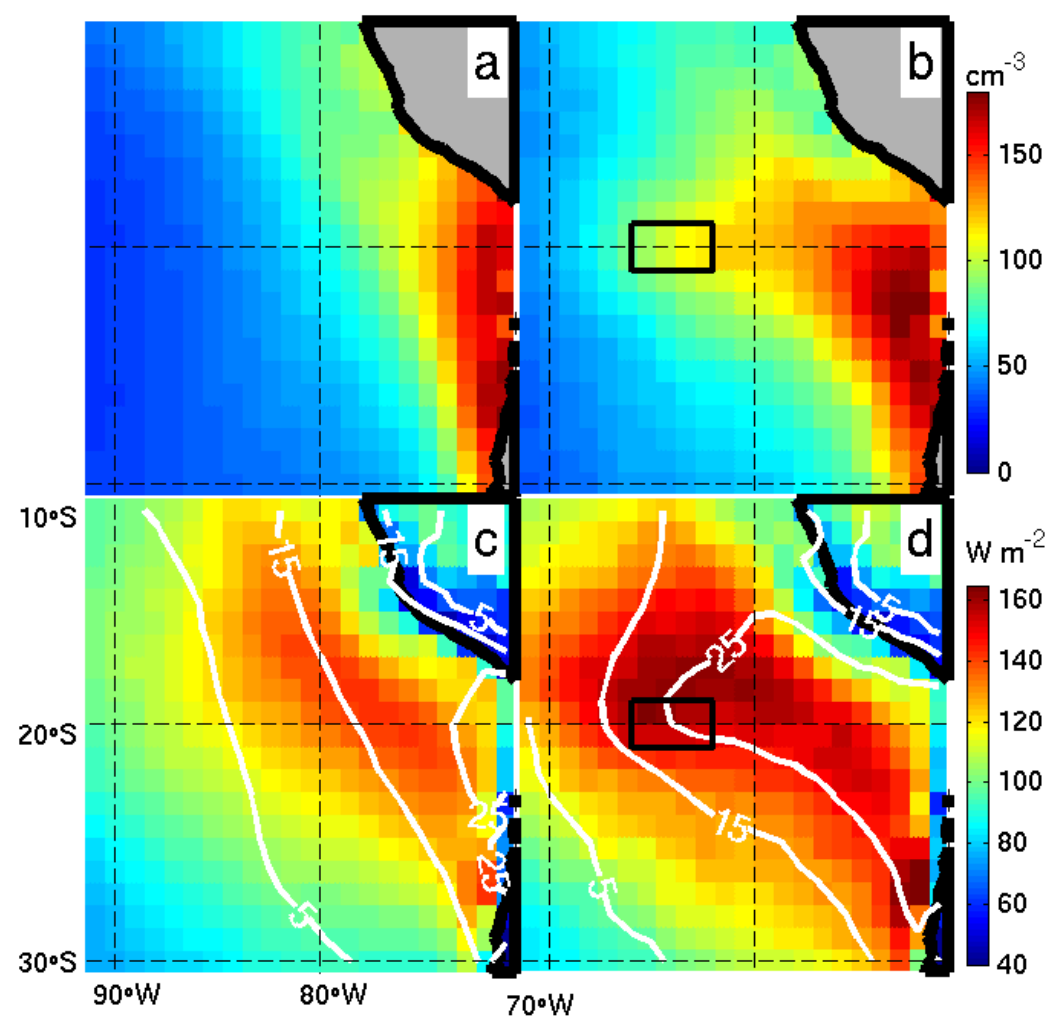

Fig. 1. MODIS time-mean cloud droplet concentration for years 2000-2008 $\left(N_{\mathrm{d}}\right)$ from (a) all retrieved days and (b) days when $N_{\mathrm{d}}$ averaged over the domain $19-21^{\circ} \mathrm{S}, 82-86^{\circ} \mathrm{W}$ is larger than $87 \mathrm{~cm}^{-3}$ (time mean plus standard deviation). Shaded colors in (c) show the diurnal mean estimate of reflected solar flux at the top of the atmosphere. The white contour lines are the time mean of the difference between the reflected solar flux and the same flux computed using the typical pristine marine $N_{\mathrm{d}}$ (average time series of $N_{\mathrm{d}}$ in the domain $30-40^{\circ} \mathrm{S}, 90-100^{\circ} \mathrm{W}$ ), which is an estimate of the Twomey effect. The contour numbers indicate $\mathrm{W} \mathrm{m}^{-2}$ of flux difference due to the increase in $N_{\mathrm{d}}$ above typical marine values. (d) is the same as (c), but composite on the same days as (b).

(VOCALS-REx, hereafter referred to as "REx"; Wood et al., 2011b) that took place during the period of 15 October16 November 2008. During REx, remote ocean (west of $80^{\circ} \mathrm{W}$ ) hooks crossed $20^{\circ} \mathrm{S}$ near times of research flights at least three times (18 October, 2 November, and 15 November), and we refer to these cases as Hooks 1, 2, and 3, respectively.

In this study we investigate the development and impact of hooks using satellite data, regional modeling, and aircraft data. Section 2 investigates the evolution of Hook1 using trajectory analysis and satellite data. We next use the Weather Research and Forecasting model with chemistry (WRF-Chem) to show that the simulated Hook1 formed predominantly by entrainment into the MBL of anthropogenic aerosols transported offshore from the Santiago region above the MBL rather than by aerosol transport within the MBL or by other means. Section 3 details WRF-Chem simulations and compares them to satellite and aircraft observations. Section 4 describes in detail cloud and chemical changes that occur during the development and decay of Hook1, identifies the meteorological conditions supporting the hook formation, and discusses its impact on albedo. Section 5 con- siders Hook 2 and Hook3 and compares them to Hook1. Conclusions follow in Sect. 6.

\section{Observational investigation of hook $\mathrm{CCN}$ sources}

\subsection{Data}

We consider VOCALS-REx observations from the NSF/NCAR C-130 and the UK BAe-146. On both platforms $N_{\mathrm{d}}$ was measured with a cloud droplet probe. Measurements of CCN were made by the University of Wyoming instrument on the C-130, which consists of a static thermalgradient chamber and optical detection system (Snider et al., 2006). We primarily consider measurements between 0.4 and $0.5 \%$ supersaturation to compare to model $\mathrm{CCN}$ at $0.5 \%$ supersaturation. DMS and $\mathrm{SO}_{2}$ were measured at $1 \mathrm{~Hz}$ on the $\mathrm{C}-130$ using an atmospheric pressure ionization mass spectrometer by Drexel University (Bandy et al., 2002; Thornton et al., 2002). More detailed instrument specifications can be found elsewhere (e.g., Allen et al., 2011; Wood et al., 2011a). 


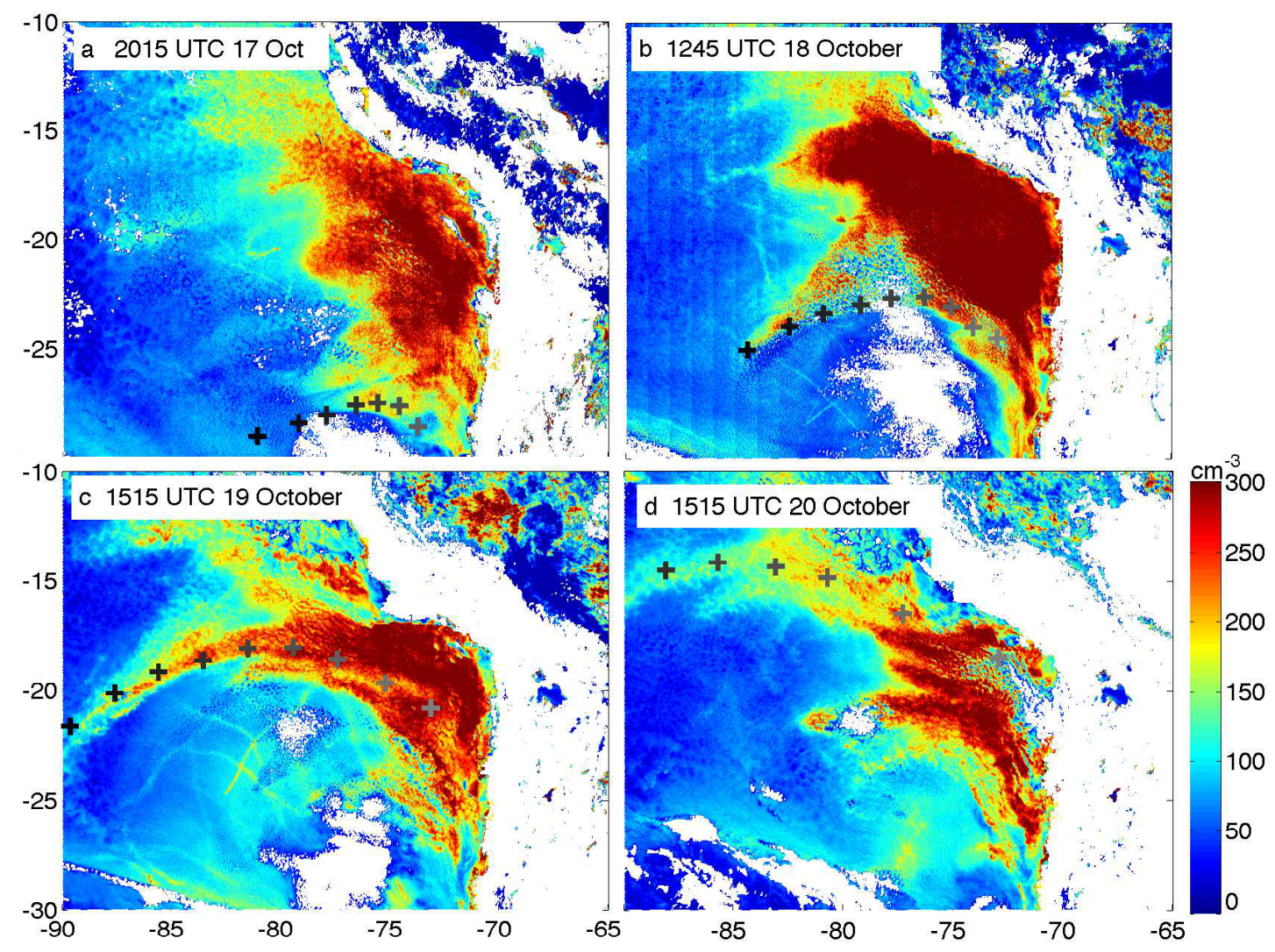

Fig. 2. Observations of Hook1 $N_{\mathrm{d}}$ derived from GOES retrievals (Sect. 2.1) on (a) 17 October at 20:15 UTC, (b) 18 October at 12:45 UTC, (c) 19 October at 15:15 UTC, and (d) 20 October at 15:15 UTC. Markers (“+”) show points along ECMWF MBL 2-D (at 950 hPa) forward and backward trajectories (see Appendix) initialized at locations along the hook on 18 October at 12:00 UTC.

MODIS satellite retrievals of $N_{\mathrm{d}}$ are limited by the daily time resolution, so we also use Geostationary Operational Environmental Satellite (GOES) retrievals of LWP and effective radius provided by Patrick Minnis' research group at NASA Langley Laboratory (Wood et al., 2011b) to compute $N_{\mathrm{d}}$ at $4 \mathrm{~km}$ horizontal resolution and $30 \mathrm{~min}$ time resolution by the method of Bennartz (2007) with a corrected formulation for the vertical condensation rate (from Albrecht et al., 1990). While the $N_{\mathrm{d}}$ accuracy depends upon solar zenith angle, midday retrievals reasonably match VOCALS flight observations and MODIS estimates (Painemal et al., 2012). The GOES- and MODIS-derived $N_{\mathrm{d}}$ from optical depth and effective radius retrievals have a strong correlation coefficient (0.88) at coincident times and a mean bias of $33.4 \mathrm{~cm}^{-3}$. This is sufficient for distinguishing events of high $N_{\mathrm{d}}$ in the remote ocean.

European Centre for Medium Range Weather Forecasting (ECMWF) operational analyses on a $0.125^{\circ} \times 0.125^{\circ}$ grid with 91 hybrid model levels at $6 \mathrm{~h}$ time resolution are used to drive 3-D and 2-D trajectories (see Appendix) presented here. Two-dimensional isobaric trajectories at a mid-MBL pressure of $950 \mathrm{hPa}$ track satellite cloud features advecting with the MBL flow quite well, lending confidence in the use of trajectory analysis. We attribute the agreement to the high quality of the ECMWF wind analysis (Bretherton et al., 2010) and the relatively weak vertical shear of winds within the MBL.

\subsection{Hook1 observations}

Of the three cases, Hook1 has the strongest anomalous $N_{\mathrm{d}}$ and extends the furthest west over the remote ocean, and is particularly striking on 19 October at 15:00 UTC (Fig. 2c). Isobaric 2-D forward and backward trajectories at $950 \mathrm{hPa}$ based on ECMWF analyses initialized from points on the hook on 19 October at 15:00 UTC trace the hook advection quite well between 18 and 20 October (Fig. 2b-d). However, prior to this on 17 October (Fig. 2a) the three outermost trajectory points have $N_{\mathrm{d}}<70 \mathrm{~cm}^{-3}$, typical of pristine marine air, and all trajectory points have significantly lower $N_{\mathrm{d}}$ than on 19 October. Although accumulated trajectory errors could potentially contribute to this (see Appendix), it appears that the hook in $N_{\mathrm{d}}$ is not explained solely by advection of an aerosol-rich airmass from the coast within the MBL. 


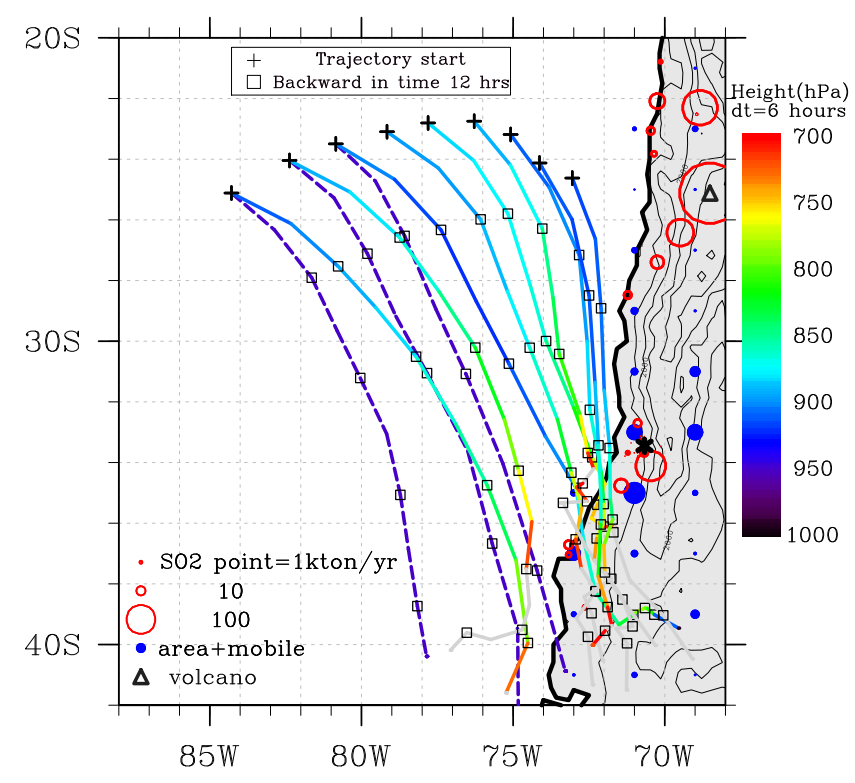

Fig. 3. ECMWF 3-D back trajectories initialized from 2-D hook MBL trajectory points on 18 October at 12:00 UTC (Fig. 2), but at the inversion level (the ECMWF level at which temperature is a minimum for relative humidity larger than $50 \%$ ) rather than $950 \mathrm{hPa}$. Colors represent trajectory heights in $\mathrm{hPa}$, gray indicating heights above $700 \mathrm{hPa}$. Squares mark $12 \mathrm{~h}$ time intervals. Dashed lines show a few $950 \mathrm{hPa}$ MBL 2-D trajectories from Fig. 2. Land contours are elevation height in $1000 \mathrm{~m}$ resolution and the "*" marks Santiago. $\mathrm{SO}_{2}$ emissions from anthropogenic and volcanic sources are shown with open red circles for point sources (including smelters and volcanos) and blue filled circles demonstrating $2^{\circ} \times 2^{\circ}$ average area + mobile urban and industrial sources.

Entrainment of FT aerosols thus warrants investigation as a significant contributing hook source. Three-dimensional back trajectories using ECMWF analyses (Fig. 3) from points along the hook (Fig. 2) at the level of the inversion (identified as the height of minimum temperature where relative humidity is larger than $50 \%$ from ECMWF profiles, which is $1-1.5 \mathrm{~km}$ at most hook locations) on 18 October at 12:00 UTC indicate subsidence and advection from the South American coast at $700-800 \mathrm{mb}$ between 34 and $37^{\circ} \mathrm{S}$ (Fig. 3). This suggests that a possible source of hook aerosols could be entrainment of FT air that has been lofted by upslope flow in the vicinity of central/southern Chile. Although the two westernmost trajectories do not quite intersect the coast, the clearly connected nature of the observed hook (Fig. 2c) suggests that these outer hook locations have similar sources. All the FT trajectories may be subject to increasing errors near the coast and close to the Andes, where upslope flow is closely confined to the orography (e.g., Toniazzo et al., 2011). Despite not intersecting the coast, the westernmost 3-D trajectories get closer to it than do the corresponding 2-D MBL trajectories (from Fig. 2, also reproduced in Fig. 3), further supporting the idea that advection of conti- nental aerosols to the remote ocean is more likely in the FT than the MBL.

The latitudes where most of the 3-D hook back trajectories approach the coast are mainly to the south of the major anthropogenic sources (including Santiago at $33.5^{\circ} \mathrm{S}, 70.7^{\circ} \mathrm{W}$, $500 \mathrm{~m}$ a.m.s.l. and the Caletones copper smelter at $34.1^{\circ} \mathrm{S}$, $70.5^{\circ} \mathrm{W}, 1700 \mathrm{~m}$ a.m.s.l.; see Fig. 3). Over land the back trajectories do not appear to originate from this source region. The small point emissions near sea level on the coast near $37^{\circ} \mathrm{S}$ are insufficient to provide significant hook CCN. Coastal biogenic, dust, and biomass burning aerosols are unlikely to cause the heavily polluted $N_{\mathrm{d}}$ seen in the hook given they cannot solely explain the large mean $N_{\mathrm{d}}$ nearer the coast (Allen et al., 2011). Volcanic emissions and copper smelters in northern Chile (north of $30^{\circ} \mathrm{S}$ ) are large sources of $\mathrm{SO}_{2}$, but hook trajectories do not indicate obvious influence from this region.

The VOCALS C-130 flight that took place on 18 October (Wood et al., 2011b) along $20^{\circ} \mathrm{S}$ and sampled the large remote $N_{\mathrm{d}}$ a few degrees north of the trajectory end points in Fig. 3 measured $100-200 \mathrm{~cm}^{-3} \mathrm{CCN}$ concentration (at a supersaturation $\sigma=0.4-0.5 \%$ ) during above-cloud flight legs, which is insufficient to explain the observed $150-300 \mathrm{~cm}^{-3}$ $N_{\mathrm{d}}$ measured during in-cloud legs and noted in satellite data. Although any CCN from the FT influencing flight-measured $N_{\mathrm{d}}$ would have been entrained upstream, there are no observations of a continuing polluted FT at flight locations. It is thus difficult with REx observations alone to establish the source of hook CCN.

\section{Model}

We use a regional chemical transport model (WRF-Chem) to understand processes controlling the origins and development of the hook features and their impact on clouds. WRF-Chem simulates most of chemical, thermodynamic, and aerosol-related processes relevant in the SEP.

\subsection{Model configuration}

We run the WRF-Chem version 3.2 (Grell et al., 2005; Fast et al., 2006) over an outer domain spanning $0-50^{\circ} \mathrm{S}, 60$ $100^{\circ} \mathrm{W}$ at $0.5^{\circ} \times 0.5^{\circ}$ horizontal resolution with 27 vertical levels, $10-12$ of which are typically in the MBL, from 15 October to 16 November 2008 following nine days of spinup. To accurately simulate the near-mountain flow and associated transport processes, we show results primarily from a nested, higher resolution domain spanning $3-40^{\circ} \mathrm{S}, 65-$ $95^{\circ} \mathrm{W}$, at $0.125^{\circ} \times 0.125^{\circ}$ resolution. For the outer domain, NCEP $1^{\circ} \times 1^{\circ}$ final analysis (FNL) winds, pressure, and thermal and moisture fields at 6-hourly time resolution provide the meteorological boundary conditions. Chemical boundary and initial conditions come from the Model for OZone and Related chemical Tracers (MOZART-4; Emmons et al., 


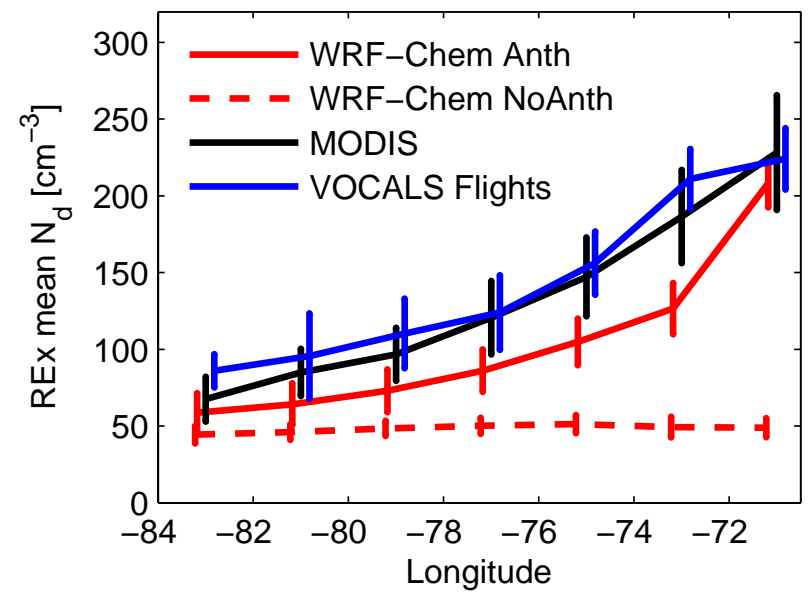

Fig. 4. VOCALS-REx mean $N_{\mathrm{d}} 19-21^{\circ} \mathrm{S}$ from MODIS retrievals (black), VOCALS flight data (blue) and WRF-Chem model output (red, at 15:00 UTC to compare with MODIS) for Anth (solid) and NoAnth (dashed) simulations in 2 degree longitude bins. Error bars show the $95 \%$ confidence interval of the standard error of the mean.

2010). An inventory compiled for VOCALS-REx described by Mena-Carrasco et al. (2010) provides point and area emissions from anthropogenic and volcanic sources. Lima $\left(12^{\circ} \mathrm{S}\right.$, $77^{\circ} \mathrm{W}$ ) emissions have been reduced by a factor of 100 because in the simulation they cause excessive column $\mathrm{SO}_{2}$ at Lima that was not observed by the Ozone Monitoring Instrument in the period 2004-2005 (Carn et al., 2007) and excessively high $N_{\mathrm{d}}$ in the northern part of the domain not present in MODIS retrievals. These emissions do not affect hook formation in the model. No biogenic (except DMS) or biomass burning emissions are included in the simulations. WRF-Chem's online wind-blown dust emissions are excluded from the simulations because they are much larger than MOZART-4 dust emissions in this region and in any case do not affect CCN concentrations. Sea spray emissions are computed following Gong et al. (1997), and do not include organic components, which are small during the VOCALS campaign (Shank et al., 2012).

The first and second aerosol indirect effects, as well as the direct and semidirect effects, are represented through interactions between aerosols, radiation, and clouds (Fast et al., 2006; Gustafson et al., 2007; Chapman et al., 2009). The Lin microphysics parameterization (Gustafson et al., 2007; Chapman et al., 2009) is used, and has been modified to include prognostic cloud droplet number. Wet deposition is implemented. The RRTM longwave radiation scheme, the Goddard shortwave radiation (Chou et al., 1998), the Grell 3-D ensemble cumulus scheme, the Monin-Obukhov surface scheme, and the NOAH land surface model comprise other chosen options. Based on code from Xin-Zhong Liang at the University of Maryland, we implement the University of Washington PBL scheme (UWPBL; Bretherton and Park, 2009) designed for the Community Atmosphere Model

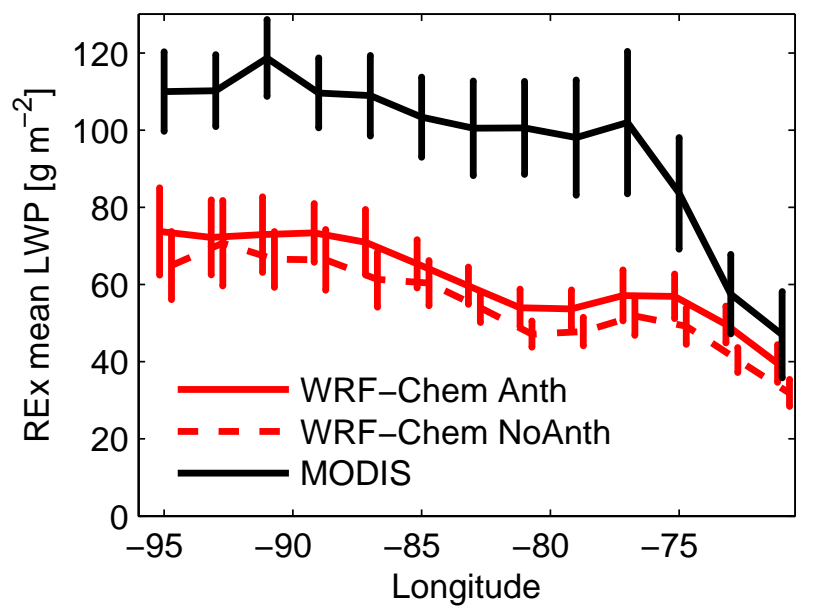

Fig. 5. VOCALS-REx mean LWP $19-21^{\circ} \mathrm{S}$ from MODIS (black) and WRF-Chem simulation at 15:00 UTC (red) for Anth (solid) and NoAnth (dashed) simulations in 2 degree longitude bins. Error bars show the $95 \%$ confidence interval of the standard error of the mean.

(CAM) to improve representation of stratocumulus in coarse resolution models.

Chemical reactions are represented via the Regional Acid Deposition Model version 2 (RADM2; Stockwell et al., 1990; Chang et al., 1990), which employs the quasi-steadystate approximation method for 38 predicted, 3 constant, and 22 diagnosed species. It includes aqueous-phase chemistry (Fahey and Pandis, 2001) that is coupled to the microphysics and aerosol schemes. Because DMS is not included in this mechanism, we have added a uniform ocean surface DMS concentration of $2.8 \mathrm{nML}^{-1}$ with a parameterized sea-air flux based on Nightingale et al. (2000) dependent on wind speed as described in the VOCA modeling experiment specification ${ }^{1}$, and we have added reactions of DMS with $\mathrm{OH}$ and $\mathrm{NO}_{3}$ to form $\mathrm{SO}_{2}$. The MADE/SORGAM modal aerosol option (Ackermann et al., 1998; Schell et al., 2001) defines aerosol properties and behavior, and tracks three size modes representing the Aitken, accumulation, and coarse modes of aerosols. Aerosol particles activate to cloud droplets using the parameterization of Abdul-Razzak and Ghan (2000), based on critical supersaturation and a Gaussian distribution of updraft speeds. The cloud droplet activation code was modified to use the UWPBL turbulent kinetic energy (TKE) output following Morrison and Pinto (2005) rather than the eddy diffusivity of heat to compute subgrid vertical velocity variance, as was done in CAM (Gettelman et al., 2010).

Three basic simulations are conducted in this study. The first simulation "Anth", which we use as our baseline simulation, has all the aforementioned emissions. A second, labeled "NoAnth", has no anthropogenic emissions and a third, "NoDMS", has all emissions other than DMS. Additional

\footnotetext{
${ }^{1}$ Available at http://www.atmos.washington.edu/ mwyant/ vocals/model/VOCA_Model_Spec.htm
} 
simulations to explore the impact of removing emissions in specific locations are described in Sect. 4.6.

\subsection{Model evaluation during REx}

Other studies have used versions of WRF-Chem to simulate the VOCALS-REx period and have been able to reproduce, with some fidelity, the key cloud and chemical features, including $20^{\circ} \mathrm{S}$ time-mean longitudinal gradients of sulfate, aerosol concentration and $N_{\mathrm{d}}$ (Yang et al., 2011; Saide et al., 2012). Although our simulations employ slightly different parameterization options and resolution, it compares similarly with REx mean conditions as these other studies, so we do not reproduce their analysis here. The gradient of REx mean $N_{\mathrm{d}}$ along $20^{\circ} \mathrm{S}$ agrees well with satellite and aircraft data (Fig. 4) even though the magnitude is underestimated by 10-30\%. Like the Yang et al. (2011) and Saide et al. (2012) simulations, the MBL aerosol and sulfate concentrations are biased low, but capture the longitudinal gradient. The sulfate mass bias is doubled without the addition of DMS to the chemical mechanism. Unlike Saide et al. (2012) we do not tune the background $\mathrm{SO}_{2}$ in the FT to match VOCALS observations, so mean $\mathrm{SO}_{2}$ and $\mathrm{CCN}$ in the FT are also lower than observed. As in Saide et al. (2012), we find that Lin microphysics leads to a mean high precipitation bias along $20^{\circ} \mathrm{S}$ compared to CloudSat using blended attenuation and Z-R methods (between 2 and 10 times as large mean precipitation rate within the range of $70-85^{\circ} \mathrm{W}$ ), which partly explains the model's low LWP bias (Fig. 5), may explain the low bias in $N_{\mathrm{d}}$ and sulfate, and possibly shortens the lifetime of aerosol species in the MBL.

\section{Hook1}

\subsection{Modeled Hook1 evaluation}

The model captures the life cycle of a hook between 17 and 20 October, shown in Fig. 6, that is in broad agreement with the observed Hook1 shown in Fig. 2, although there are some differences in its timing and extent. On 19 October at 15:15 UTC the observed $N_{\mathrm{d}}$ spatial pattern (Fig. 2c) is a clear example of what we define as a hook. At this time, there is a modeled hook (Fig. 6e), but it is shifted several degrees to the north of the observed hook. The modeled hook $24 \mathrm{~h}$ earlier (Fig. 6c) more accurately represents the observed hook at 15:00 UTC on 19 October, indicative of a timing bias. In addition, the westward tip of the modeled hook is about 5 degrees further west than the observed hook. The $N_{\mathrm{d}}$ maxima in the modeled hook are comparable to those in the observed hook, and the arched shape of the hook is well captured, but the observed hook is considerably narrower than the modeled hook. The time evolution of $N_{\mathrm{d}}$ is in good agreement with observations, with both showing a persistent feature advecting northward through the region over several days before decaying.
On the other hand, several features of the pattern of observed and modeled $N_{\mathrm{d}}$ do not match. The model simulates a second large hook north of the one we have focused on (Fig. 6b, c). Although the observations do indicate a protuberance of polluted $N_{\mathrm{d}}$ reaching west of $80^{\circ} \mathrm{W}$ ahead of Hook1 (Fig. 2b, c), this observed feature is not so clearly hook shaped, does not extend as far westward, and is more spatially separated from Hook1 than in the model (Figs. 2b and $6 \mathrm{c}$ ). The model also does not reproduce the high $N_{\mathrm{d}}$ values east of $75^{\circ} \mathrm{W}$ between 18 and $26^{\circ} \mathrm{S}$.

Model MBL 2-D trajectories accurately follow the modeled hook feature (Fig. 6). Trajectories are computed both forward and backward starting from points along the maximum model $N_{\mathrm{d}}$ on 19 October at 03:00 UTC to trace both the development and decay of the modeled hook. Trajectories are initialized two model levels below the inversion, between 910 and $950 \mathrm{hPa}$, and are computed with horizontal wind components only. Figure 6 suggests that the modeled hook along these trajectories coincides with a large source of $\mathrm{CCN}$ just above the inversion. Over time, this modeled FT source decreases in number concentration due to entrainment and falls behind the hook due to vertical wind shear.

Measured $\mathrm{SO}_{2}$ and $\mathrm{CCN}$ concentration (at $\sigma=0.4-0.5 \%$ ) in the FT during the $\mathrm{C}-130$ Hook1 flight (on 18 October) indicates the flight did not sample a strong FT aerosol source (Fig. 7) that can explain the coincident large $N_{\mathrm{d}}$ (e.g., Fig. 2b). The time offset between model and satellite observations of the peak hook $N_{\mathrm{d}}$ crossing $20^{\circ} \mathrm{S}$ is $24 \mathrm{~h}$, so flight data are compared with model output $24 \mathrm{~h}$ earlier (Fig. 7), on 17 October. Although flight $\mathrm{SO}_{2}$ values are in agreement with the branch of model $\mathrm{SO}_{2}$ elevated above the background slightly south of the flight measurements, this is partly due the mean bias in the model FT SO 2 concentrations. The 4050 pptv observed in the remote ocean FT is slightly larger than the $20-40$ pptv observed on average by C-130 flights during REx along $20^{\circ} \mathrm{S}$ (Allen et al., 2011), but because the $\mathrm{CCN}$ measured in the FT is also not notably large, this was not interpreted as a significant FT pollution event. The CCN flight measurements agree very well with the model (except in the furthest SW leg), which inspires some confidence in the model representation. The model suggests that a large FT CCN source coincided with Hook1 (Fig. 7b), but further south than the flight measured. Additionally this modeled FT CCN source contributes to the northern $N_{\mathrm{d}}$ hook that is erroneously large as explained above. It is likely that during the flight $N_{\mathrm{d}}$ was large due to a FT source that had already entrained. At the comparison time, modeled $N_{\mathrm{d}}$ is not large in the flight region (Fig. 6a), but later times in the model (e.g., Fig. 6b) indicate that large $N_{\mathrm{d}}$ ahead of a large FT CCN source can occur and is modeled, just not in the same times and places as observed. The flight did not sample the hook edge, and thus likely simply did not sample a region of entrainment of high concentrations of FT CCN. 


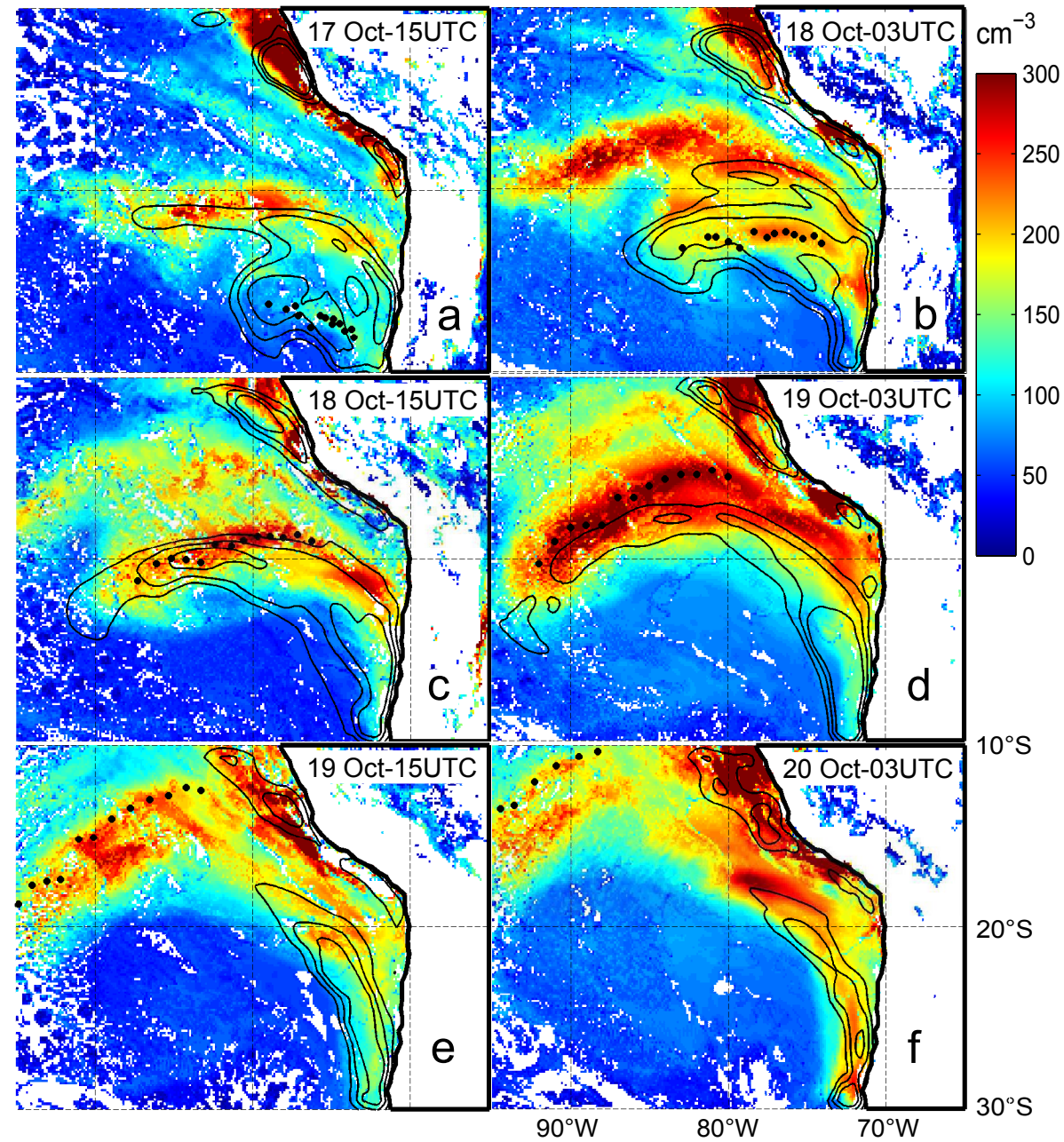

Fig. 6. Model $N_{\mathrm{d}}$ (colors) with filled black circle markers following $13 \mathrm{WRF}-\mathrm{Chem}$ 2-D MBL trajectories. Trajectories are initialized from points along the peak $N_{\mathrm{d}}$ on 19 October at 03:00 UTC (d) two model levels below the inversion $(\sim 910-950 \mathrm{hPa})$. They are computed forward until they reach the NW corner of the domain, and backwards until 17 October at 03:00 UTC. Black contours are CCN at $0.5 \%$ supersaturation in the model layer above the inversion at 200,300, and $400 \mathrm{~cm}^{-3}$.
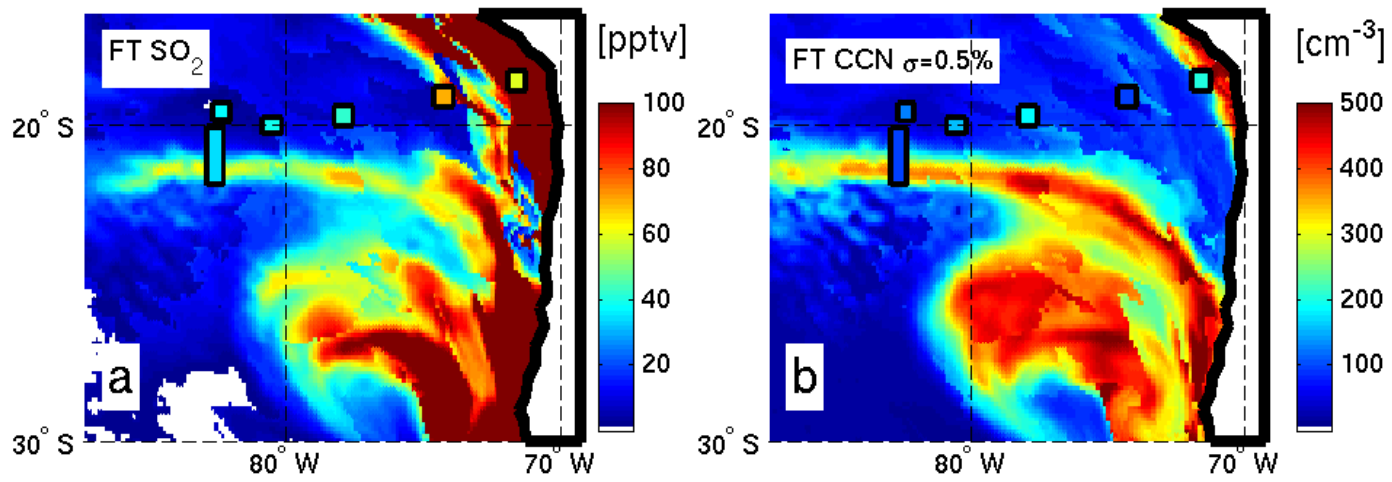

Fig. 7. Contours of model (a) $\mathrm{SO}_{2}$ and (b) $\mathrm{CCN}$ at $\sigma=0.5 \%$ in the model level above the inversion on 17 October at 15:00 UTC, $24 \mathrm{~h}$ before the VOCALS C-130 RF02 flight (13:00-21:00 UTC 18 October) to correct for model and satellite observations time offset of $N_{\mathrm{d}}$ (Figs. 2 and 6). Superimposed rectangles show above-cloud flight leg mean data $\mathrm{SO}_{2}$ measurements and $\mathrm{CCN}$ when measured for $\sigma=0.4-0.5 \%$. 

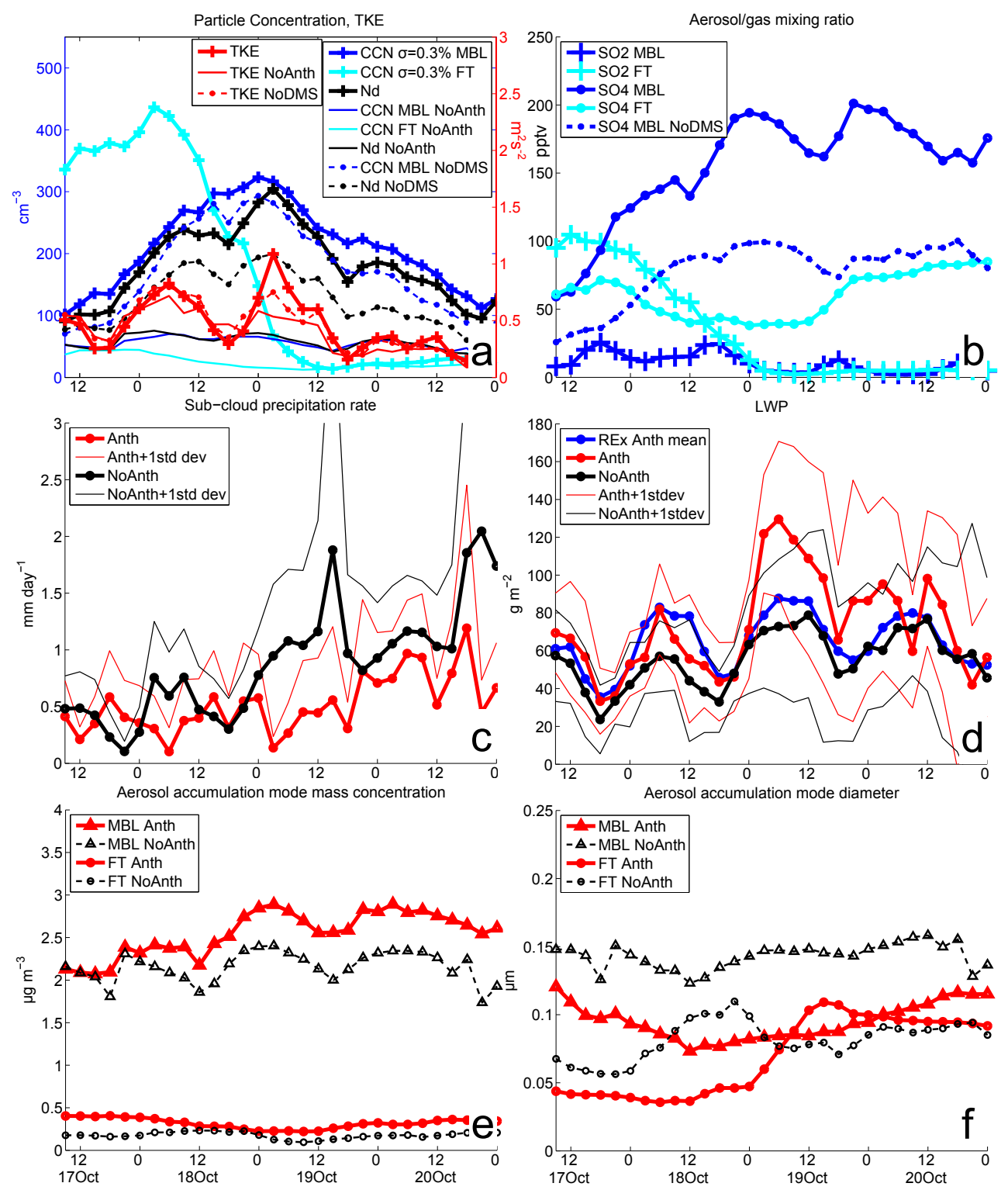

Fig. 8. Average of cloud and aerosol properties interpolated along $952-\mathrm{D}$ hook trajectories, computed in the same manner as those marked Fig. 6, both in the model layer just above the inversion (FT) and in the MBL at the cloud level. (a) FT CCN (cyan) and MBL CCN (blue) at $0.3 \%$ SS with $N_{\mathrm{d}}$ (black) and turbulent kinetic energy (red). The Anth simulation has "+" markers. Lines without markers are the NoAnth simulation and circle markers with dashed lines indicate the NoDMS simulation. (b) $\mathrm{SO}_{2}$ ("+") and $\mathrm{SO}_{4}$ (circles) in the FT (cyan) and MBL (blue). The dashed blue line indicates NoDMS MBL SO 4 . In (c-f) properties in the Anth (red) and NoAnth (black) are compared. Thin solid lines indicate 1 standard deviation outside the mean of hook points. (c) Precipitation rate simulations at sub-cloud level. (d) LWP and REx mean LWP at the same time of day at hook trajectory locations (blue). Accumulation-mode aerosol mass and computed accumulation-mode diameters are shown in the (e) and (f) in the MBL (triangles) and FT (circles).

\subsection{Interpolation over 2-D trajectories}

\subsubsection{Hook development}

Figure 8 shows cloud and aerosol properties interpolated along WRF-Chem 2-D MBL backward and forward trajectories initialized at a set of points along the hook at 03:00 UTC on 19 October (see Fig. 6), and demonstrates the development and decay of Hook1. We construct a time series of the average in-cloud $N_{\mathrm{d}}$ over all trajectories with LWP $>0.01 \mathrm{~g} \mathrm{~m}^{-2}$ (Fig. 8a). The concentration $N_{\mathrm{CCN}, \mathrm{FT}}$ of CCN at $0.3 \%$ supersaturation in the model layer above the marine inversion peaks at over $\sim 400 \mathrm{~cm}^{-3}$, some $15 \mathrm{~h}$ before the peak of $\mathrm{CCN}$ within the MBL, and decreases rapidly 
thereafter. By the time of peak $N_{\mathrm{d}}$, fewer than $50 \mathrm{~cm}^{-3}$ FT $\mathrm{CCN}$ remain. During the second half of the hook life cycle, $N_{\mathrm{CCN}, \mathrm{FT}}$ decreases to low levels (Fig. $8 \mathrm{a}$ ) and precipitation reaching the surface increases (not shown). Air entrained from the FT has low CCN concentrations, so $N_{\mathrm{CCN}, \mathrm{MBL}}$ and $N_{\mathrm{d}}$ decrease without a major source to replace droplets lost to precipitation and dilution. This provides strong evidence that entrainment of FT aerosol is a dominant source of simulated hook aerosol and $N_{\mathrm{d}}$. The earlier increase of $N_{\mathrm{CCN}, \mathrm{FT}}$ (Fig. 8a) is due to the arrival at the inversion of a subsiding aerosol layer (see Sect. 4.4).

The peak in hook $N_{\mathrm{d}}$ lags the $N_{\mathrm{CCN}, \mathrm{FT}}$ peak by $24 \mathrm{~h}$ (Fig. 8a). The increase in $N_{\mathrm{d}}$ mirrors the increase in $N_{\mathrm{CCN}, \mathrm{MBL}}$ until $18 \mathrm{~h}$ before they both peak. This period of separation in CCN and $N_{\mathrm{d}}$ is explained by a reduced supersaturation maximum and therefore a lower fraction of $\mathrm{CCN}$ activated in the clouds during daytime because TKE is stabilized by solar absorption (local transition from night to day occurs at $\sim 12: 00$ UTC). This effect is also seen during the subsequent day starting at 12:00 UTC on 19 October. The daytime decline in TKE reduces the turbulent vertical velocity variance and thus maximum effective in-cloud supersaturation, which increases in the size of the smallest particle activated and decreases the fraction of aerosol particles that become droplets. The daytime separation between $N_{\mathrm{d}}$ and $N_{\mathrm{CCN}, \mathrm{MBL}}$ is indicative of a population of small CCN entrained from the FT that is strongly sensitive to the maximum supersaturation achieved during the activation process. That is, there are small CCN that are not activated but would in a more turbulent cloud with higher supersaturation.

The activation of these additional CCN occurs during the 6-9 h period leading to peak $N_{\mathrm{d}}$, which also corresponds to a peak in TKE. The increase in $N_{\mathrm{CCN}, \mathrm{MBL}}$ is the essential condition enabling hook formation, but MBL turbulence and chemistry also influences the variability in $N_{\mathrm{d}}$ over the life cycle of a hook. As the hook feature forms, $\mathrm{FT} \mathrm{SO}_{2}$ concentrations are higher than in the MBL, so entrainment is a source of $\mathrm{SO}_{2}$ (Fig. 8b), which is oxidized to sulfate in the MBL. This entrainment source explains some, but not all, of the large increase in $\mathrm{MBL} \mathrm{SO}_{4}$ aerosol mass during the hook growth period. A surface sulfur source is also important as demonstrated by the fact that the $\mathrm{MBL} \mathrm{SO}_{4}$ mass is reduced by $\sim 40 \%$ in the NoDMS simulation (Fig. 8 b). Despite the importance of the surface DMS source for increasing MBL sulfate aerosol mass, $N_{\mathrm{CCN}, \mathrm{MBL}}$ is not strongly sensitive to the surface DMS source (Fig. 8a). This is primarily because the $\mathrm{SO}_{2}$ mainly condenses onto and enlarges existing particles. While this does move some particles into the $\mathrm{CCN}$ size range, this is not a major effect, consistent with previous modeling studies (e.g., Woodhouse et al., 2010).

The value of $N_{\mathrm{d}}$ is more sensitive than is $N_{\mathrm{CCN}, \mathrm{MBL}}$ to the inclusion of DMS (Fig. 8a). This is also seen in Fig. 9a and $\mathrm{b}$, which compares the $N_{\mathrm{d}}$ fields at one particular time for NoDMS with the control Anth simulation. This sensitivity is due to a complex consequence of several factors, including changes in particle size and TKE differences (Fig. 8a). However, another consideration is that in the NoDMS run, the hook in $N_{\mathrm{d}}$ is displaced a few degrees southeast, so the maximum $N_{\mathrm{d}}$ is not sampled by the trajectories shown in Fig. 8a. This offset may be partly due to simulation meteorological variability and not directly related to DMS.

Although the hook event results from significant entrainment of CCN, the total accumulation-mode aerosol mass per unit volume above the inversion is less than $0.5 \mu \mathrm{g} \mathrm{m}^{-3}$, much smaller than the $2-3 \mu \mathrm{g} \mathrm{m}^{-3}$ averaged in the MBL (Fig. 8e). The mean accumulation-mode dry volume diameter (calculated from mass and number values) is only $\sim 0.04 \mu \mathrm{m}$ in the FT vs. $\sim 0.1 \mu \mathrm{m}$ in MBL (Fig. $8 \mathrm{f}$ ) during hook development. With sea salt aerosols comprising a large fraction of the accumulation-mode aerosol mass in the MBL, entrainment of small FT particles has little impact on the MBL mass. The small relative increase in MBL mass following the hook is likely due to condensation of $\mathrm{SO}_{2}$ oxidized from DMS on entraining aerosols. Thus the FT source is comprised of numerous small aerosols, strongly impacts the MBL aerosol number concentrations, and has little impact on aerosol mass within the hook. It is also worth noting that the contribution of organic aerosols to the overall aerosol mass in the FT immediately above the hook is only $10-20 \%$ in the model, and so most of the contribution to CCN associated with the hook is from sulfate.

\subsubsection{Hook impacts on cloud properties}

Without anthropogenic aerosols (in the NoAnth simulation), no hook forms (Fig. 9). Thus, comparing the cloud properties in the NoAnth and Anth simulations at the same locations/times allows us to distinguish cloud macrophysical changes due to anthropogenic aerosols from those due to meteorological changes. Their differences between the NoAnth and Anth simulations maximize near peak hook $N_{\mathrm{d}}$ ( $\sim$ 03:00 UTC on 19 October, Fig. 8a) and show diurnal modulation. The hook aerosols cause increased TKE (Fig. 8a) and LWP (Fig. 8d), most likely due to the suppression of precipitation due to increased CCN (Fig. 8c) and associated reduction in stabilization (Stevens et al., 1998; Ackerman et al., 2004; Wood, 2007). The precipitation below cloud base is $1-2$ mmday $^{-1}$ in the NoAnth simulation right around the time of the peak hook $N_{\mathrm{d}}$, and is cut by roughly $50 \%$ due to the hook aerosols. A strong diurnal cycle in LWP is found in both the Anth and NoAnth cases (Fig. 8d), but hook aerosols increase LWP more at night (especially during the night of the peak hook $N_{\mathrm{d}}$ ). This is likely a consequence of the strong coincident precipitation suppression. We examine the impacts of these cloud macrophysical changes on the albedo in Sect. 4.3. From 00:00 to 09:00 UTC on 20 October, surface precipitation is suppressed compared to that in the NoAnth simulation(not shown), but sub-cloud base precipitation rate is only weakly suppressed. Anth LWP is much smaller than the night before due to a weakened influence 


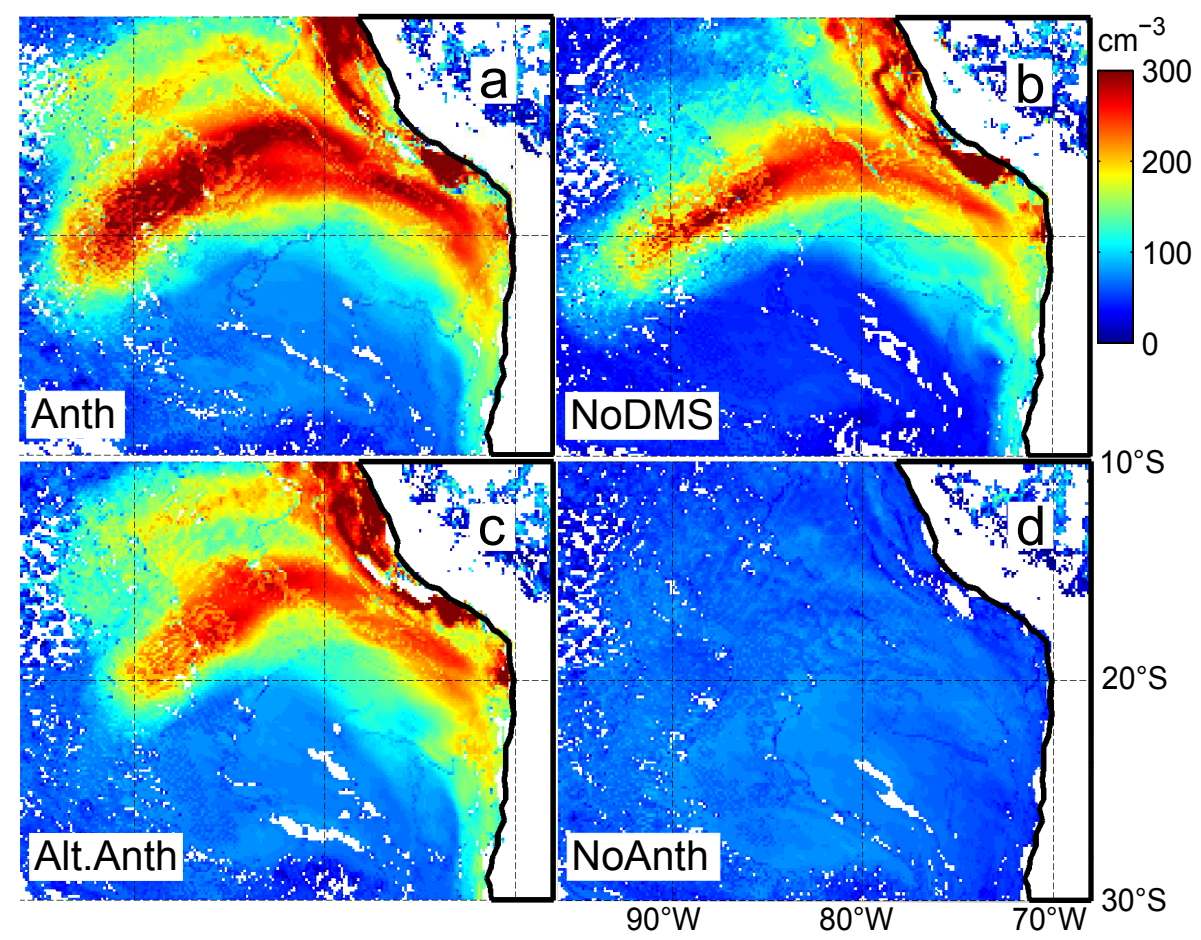

Fig. 9. Snapshots of $N_{\mathrm{d}}$ on 19 October at 03:00 UTC from different simulations: (a) Anth, full anthropogenic emissions, includes DMS; (b) NoDMS, full anthropogenic emissions, no DMS; (c) Alternative Anth: no anthropogenic emissions south of $30^{\circ} \mathrm{S}$, east of $70^{\circ} \mathrm{W}$, includes DMS; (d) NoAnth, no anthropogenic emissions, includes DMS.

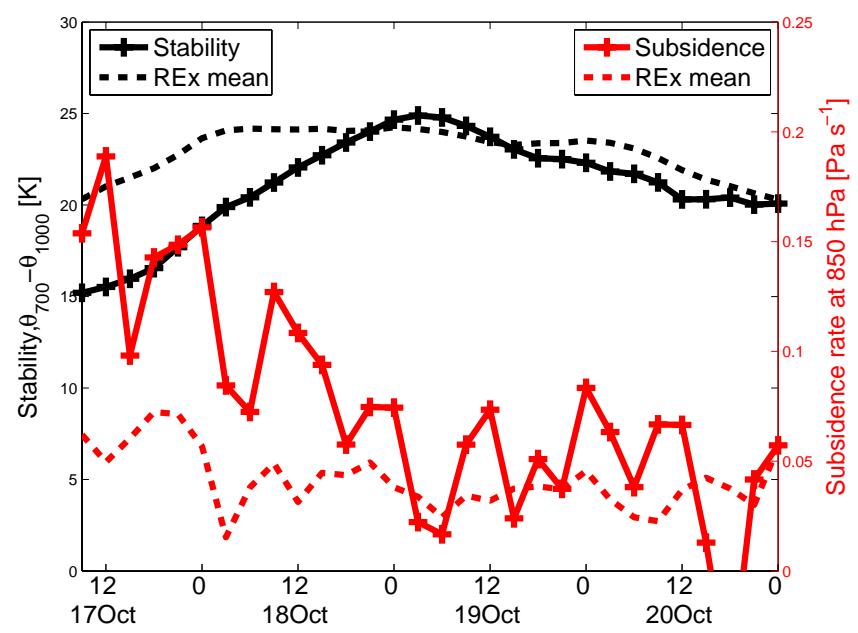

Fig. 10. Average stability (black) and $850 \mathrm{hPa}$ subsidence rate (red) interpolated over Hook1 2-D trajectories (same trajectories used in Fig. 8). Stability is defined as the difference in potential temperature between $700 \mathrm{hPa}$ and $1000 \mathrm{hPa}\left(\theta_{700}-\theta_{1000}\right)$ and subsidence is the grid-scale vertical velocity in pressure units $\left(\mathrm{Pas}^{-1}\right)$. Crosses mark the Anth simulation and dashed lines denote the REx mean at the locations and times of day of the Hook1 trajectories. of hook aerosols and dips strongly at 09:00 UTC. This does not coincide with a more rapid $\mathrm{CCN}$ loss rate than in the NoAnth simulation, so may indicate a process that reduces droplet size during hook decay.

For context, Fig. 8d also shows the mean LWP from the Anth simulation at the same times of day/locations from the entire REx period. Other than exhibiting a strong diurnal cycle, the REx mean LWP does not change markedly following the northward motion of the evolving trajectory position, indicating that the LWP evolution along the trajectory in the Anth and NoAnth runs is not driven by geographical variation in meteorology. That the nighttime LWP increases from the night of 17-18 October to the following night in the NoAnth simulation means some of the increase in Anth simulation nighttime LWP is caused by meteorological peculiarities of the hook event. During the initial hook formation stages subsidence is stronger than average (Fig. 10), which causes lower inversion heights than average (not shown) despite weaker lower tropospheric stability than in the REx mean. Following the developing hook the stability increases, which maintains the strong capping inversion and weakens entrainment, which suppresses the lifting of the cloud base level. The weakening subsidence allows the MBL top to rise despite the strengthening stability, so cloud thickness and LWP increase. 


\subsection{Impact of hook on albedo}

LWP and $N_{\mathrm{d}}$ (discussed above) and CF (not shown) are, on average over the hook, greater in the Anth simulation than in the NoAnth simulation due to the hook-forming aerosols (Fig. 8), so the secondary indirect effects of anthropogenic emissions generally enhance the Twomey effect on hook albedo. We estimate model albedo using model-derived $N_{\mathrm{d}}$, LWP, and CF following the method of George and Wood (2010). This allows us to separate the Twomey effect, the impacts of microphysics $\left(N_{\mathrm{d}}\right)$, from albedo changes due to secondary effects (LWP and CF). These computed albedo values are about $10 \%$ larger than albedo derived from model top-of-atmosphere shortwave flux due to the influence of atmosphere above the clouds not addressed by the computation and differences in scattering assumptions between the albedo computation and the model. A similar difference between the cloud-top and top-of-atmosphere albedo using satellite data was noted in George and Wood (2010). For each day following the hook the daily solar-insolation-weighted mean albedo is computed to capture the net hook AIE impact. The albedo from the Anth simulation along the hook trajectory is $35-50 \%$ larger than in the NoAnth simulation (Fig. 11). Albedo computed using the Anth simulation macrophysical properties but NoAnth values of $N_{\mathrm{d}}$ (blue circles in Fig. 11) demonstrates that the Twomey effect contributes $\sim 50-70 \%$ of the hook albedo enhancement over that in NoAnth, while aerosol-induced LWP and CF changes and meteorological variability between Anth and NoAnth simulations contribute the rest. Note that Fig. 11's representation of the Twomey effect uses the Anth simulation as the reference case, which is different from studies using global climate models that would typically use NoAnth as the reference. The $\sim 20 \%$ temporal increase in Anth albedo following the hook (from 0.41 to 0.49 ) demonstrates the significant change in albedo that an individual hook event can cause. The smaller $(\sim 13 \%$; 0.3 to 0.34 ) temporal increase in NoAnth albedo is due partly to the increase in LWP associated with the increasing stability and weakening subsidence. Removing DMS from the simulation causes a $20-25 \%$ reduction in hook albedo, and indicates a systematic effect of aerosol growth due to DMSderived $\mathrm{SO}_{2}$ (Fig. 11). Before the hook has formed on 17 October, excluding DMS reduces albedo to a magnitude similar to the NoAnth simulation, and a $\sim 43 \%$ temporal increase in the NoDMS hook albedo indicates that omitting this important $\mathrm{SO}_{2}$ source would cause an overestimation in the albedo change associated with the hook. DMS thus impacts the background MBL properties that noticeably affect the entrained hook aerosols and resulting radiative changes. However, DMS is overestimated in the model compared to observations (Yang et al., 2011), so the impact of DMS on results is likely also overestimated.

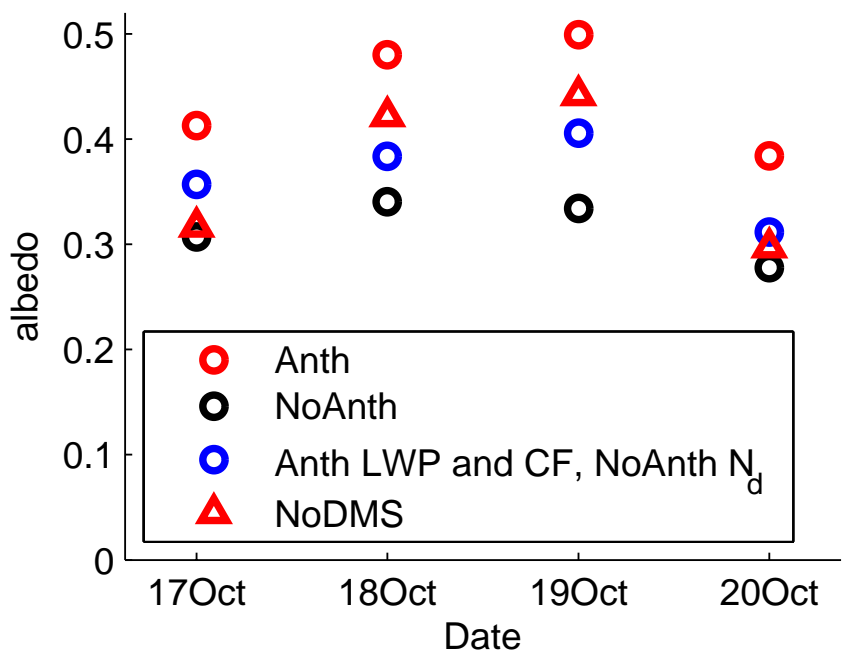

Fig. 11. Average albedo interpolated over Hook1 2-D trajectories (same trajectories used in Fig. 8) and averaged over each day, weighted by solar insolation. The Anth (red circles), NoAnth (black), and NoDMS (red triangles) simulations are shown. The blue circles are albedo computed using Anth LWP and CF, and NoAnth $N_{\mathrm{d}}$ and include a correction for biases caused by WRFChem's binary CF (average of the Twomey effect estimates using Anth and NoAnth as the base simulations with constant LWP and $\mathrm{CF})$. The Twomey effect estimate is thus the difference between red and blue circles, while secondary effects are represented by the difference between blue and black circles.

\subsection{3-D pathway of hook FT aerosol}

The evolution of aerosol and cloud properties along 2-D MBL trajectories allows us to examine how the hook is formed by entrainment of FT aerosols, but this cannot identify the original source of the aerosols, nor does it explain the meteorological conditions that allow for the transport of pollution to the remote ocean. Model 3-D back trajectories (not shown) from regions of large FT CCN indicate that the Santiago region $\left(33-35^{\circ} \mathrm{S}, 70-72^{\circ} \mathrm{W}\right)$ is the dominant source of aerosols and precursors for the hook. It is more illustrative to examine forward 3-D trajectories initialized among the Santiago-region sources that eventually transport offshore and contribute to the hook CCN. The circle markers in Fig. 12 show one such representative trajectory. It begins on 15 October at 18:00 UTC at $2 \mathrm{~km}$ above ground near the surface above the Caletones smelter (34.125 $5^{\circ} \mathrm{S} 70.5^{\circ} \mathrm{W}, 1700 \mathrm{~m}$ a.m.s.l.). The Caletones smelter contributes $\mathrm{SO}_{2}$ emissions of $108 \mathrm{kton} \mathrm{yr}^{-1}$, or $\sim 40 \%$ of the total $\mathrm{SO}_{2}$ emissions south of $28^{\circ} \mathrm{S}$ and west of the Andes. Although smelters alone make a relatively small contribution to the mean SEP aerosol population (Twohy et al., 2012), this trajectory represents one pathway in which copper smelter emissions may reach the remote ocean. The left panels of Figs. 13 and 14 show longitude-height slices at key times at the latitude of the trajectory location; the right panels in 
Fig. 13 show corresponding REx mean conditions. The trajectory is situated within a plume of high CCN concentrations (cyan contours) and $\mathrm{SO}_{2}$ concentrations (yellow contours) and reaches the inversion level near $80.5^{\circ} \mathrm{W}, 20.5^{\circ} \mathrm{S}$ on 18 October at 15:00 UTC (Fig. 14c), contributing aerosols to MBL in the Hook1 growth phase (see Fig. 8). During the early days of this trajectory (15-16 October), anomalously strong southward Andes barrier winds (Rahn and Garreaud, 2010a; Toniazzo et al., 2011) prevail north of $37^{\circ} \mathrm{S}$ over the Andes (compare left and right panels, Fig. 13a-d), causing stronger than average southward transport of Santiagoregion emissions. This is supported by an upper-level trough (Fig. 15b) ahead of a southeastward shifting subtropical high and cyclonic flow ahead of this feature near Santiago. The polluted air advects southward along and up the Andes and reaches $37-40^{\circ} \mathrm{S}$, a typically clean region with few local pollution sources (Fig. 13f), on 16 October. During this period of southward transport, ascent over the Andes is also stronger than average (Fig. 13a vs. 13b). Some of the vertical enhancement may be due to the normal diurnal cycle as in the vicinity of the Andes the mountain breeze maximum and land-sea circulation are associated with ascent later in the day (Toniazzo et al., 2011). At the trajectory start time $(\sim 15: 00 \mathrm{LT})$ ascent is therefore expected. However, there is also stronger than average onshore flow aloft (due to the anomalous cyclonic flow) encountering the Andes barrier (Fig. 13a, b) and enhancing the vertical motion. The upward motion leads to a large plume of $\mathrm{SO}_{2}$ and $\mathrm{CCN}$ rising to over $5 \mathrm{~km}$ near $36^{\circ} \mathrm{S}$ nine hours after the trajectory start (Fig. 13c). The trajectory actually moves over the crest of the Andes. At this time, the flow at 3-6 km contains little or no zonal component as the trajectory nears the center of the mid-tropospheric cyclone (Fig. 15b).

The shift of the subtropical high towards the coast on 16 October drives strong surface southerlies at $36^{\circ} \mathrm{S}$ and the approaching upper-level trough encourages onshore flow at $700 \mathrm{hPa}$ to the north of $36^{\circ} \mathrm{S}$ and offshore flow to the south (Fig. 15b). Normally, the flow near and south of Santiago is onshore throughout the lower troposphere (Fig. 13b, d, f) and does not therefore carry urban emissions over the remote ocean. On average, surface emissions in the Santiago area advect weakly northward (similar latitude shown in Fig. 13b), but if lofted high enough ( $>2 \mathrm{~km}$ ) to reach the Andes northerly barrier flow, the primary direction of transport is southward. In the Hook1 case, the pollution plume, having moved southward to $39^{\circ} \mathrm{S}$, is then subject to offshore flow over a deep layer from the surface to over $6 \mathrm{~km}$ (Fig. 13e). This day coincides with the peak in the strength of the subtropical high (Fig. 15b), which is shifted southeast of its REx mean (Fig. 15d). The lower height of the Andes at $39^{\circ} \mathrm{S} \mathrm{com-}$ pared with Santiago's latitude also reduces their blocking effect and allows westward flow at lower levels and a deep column of offshore aerosol transport.

Southward transport of Santiago-region emissions occurs regularly and is visible in the modeled $\mathrm{REx}$ mean $\mathrm{SO}_{2}$ con- centrations. For example, at $36^{\circ} \mathrm{S} \mathrm{SO}_{2}$ concentrations exceeding 100 pptv extend above $4 \mathrm{~km}$ on average (Fig. 13d). Usually, this plume is advected eastward across the Andes; it is the enhancement of this feature (over $500 \mathrm{pptv}$ above $4 \mathrm{~km}$, Fig. 13c) due to the strengthened southward winds, combined with meteorological conditions conducive to subsequent offshore flow, that allows for the formation of the modeled Hook1. Nucleation of the enhanced $\mathrm{SO}_{2}$ in this specific case is also important to create the high $\mathrm{CCN}$ seen in Hook1 but not in the mean state.

By 06:00 UTC on 17 October (Fig. 14a) northwestward flow has looped the trajectory back to its starting latitude, but west of its starting point, by which time the subtropical high has partly relaxed towards its climatological mean (Fig. 15c). As the upper-level trough nears the coast it suppresses the normal zonal flow and induces a strong northward flow, especially at $74-75^{\circ} \mathrm{W}$ (Fig. 12). Together with stronger than average subsidence west of the trough on 17 October, between 06:00 and 21:00 UTC on 17 October (Fig. 14a, b), the trajectory advects westward by only about $1^{\circ}$, but northward by about $7-8^{\circ}$ and subsides by about $1.5 \mathrm{~km}$. The top of the plume also drops substantially, and for the remainder of the FT plume lifespan it subsides and spreads above the inversion level. By the time the trajectory reaches $20.5^{\circ} \mathrm{S}$ on 15:00 UTC 18 October, the plume is entraining into the MBL and its vertical extent reaches only to $1 \mathrm{~km}$ above the inversion (Fig. 14c). Whether a particular polluted plume in the FT contributes to a hook downstream is dependent on the timing, magnitude, and location of offshore flow and its altitude above the stratocumulus. For example, at $36^{\circ} \mathrm{S}$ on 03:00 UTC 16 October (Fig. 13c), a plume of $\mathrm{SO}_{2}$ between 1 and $3 \mathrm{~km}\left(72-75^{\circ} \mathrm{W}\right)$ extends offshore in low-level easterlies. But as it advects northwards (not shown) it encounters onshore flow associated with near-coast low pressure (Fig. 15c) and never contributes to remote CCN. The broad polluted plume already existing in the FT at $34^{\circ} \mathrm{S}, 75-81^{\circ} \mathrm{W}$ at the start of the shown trajectory (Fig. 13a) advects northward until around $28^{\circ} \mathrm{S}$ (not shown), at which point westward flow associated with the subtropical high transports the plume out over the ocean, providing the source aerosol for the modeled hook to the north of (i.e., preceding) Hook1 (Fig. 6b). As mentioned in Sect. 4.1, this feature does not match satellite observations well but may represent a noted protuberance of high $N_{\mathrm{d}}$ ahead of Hook1. Back trajectories indicate this modeled plume advected offshore near $39^{\circ} \mathrm{S}$ on 14 October and before that had traveled southward from the Santiago region, similar to the transport mechanism associated with Hook1. This offshore flow is associated with the same approaching ridge/trough that affects Hook1, and a strong surface coastal low on 13 October.

Figure 12 shows two additional 3-D trajectories, initialized in a similar elevated $\mathrm{SO}_{2}$ plume presumably due to earlier southward transport. Despite the difference in starting locations, all three trajectories advect offshore at a similar time, but at different pressures (from $570 \mathrm{hPa}$ to $680 \mathrm{hPa}$ ). The 


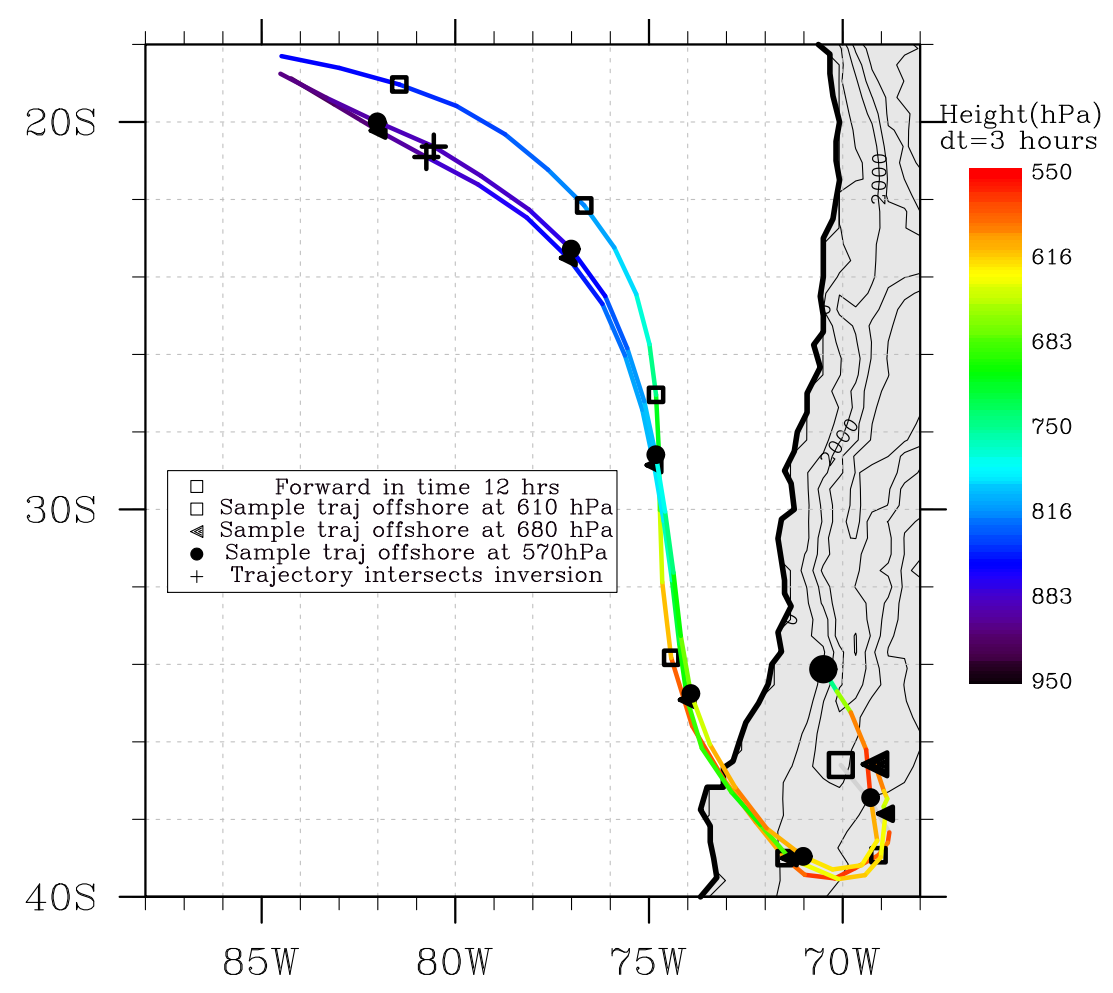

Fig. 12. Three forward WRF-Chem trajectories from 15 October at 18:00 UTC to 19 October at 00:00 UTC that follow polluted CCN in the FT from land to Hook1 and advect offshore at different heights. Markers indicate $12 \mathrm{~h}$ intervals and marker shapes distinguish the trajectories. Circle markers follow the trajectory shown in Figs. 13 and 14.

lower two trajectories follow very similar paths. The highest trajectory ultimately contributes to the hook further west and later than the lower two as it takes longer to subside. However, the faster speed at which this trajectory travels is offset by the weakened influence of subtropical high induced easterly flow at these higher altitudes, increasing the distance it must travel to the remote ocean compared to the lower trajectories. Thus, in this case, transport of high CCN over the remote ocean depends on offshore flow at a level that is high enough to avoid intersecting the MBL before reaching the remote ocean but low enough to be turned westward by the low level flow between 20 and $30^{\circ} \mathrm{S}$.

The model 3-D trajectory traced in Figs. 13 and 14 crosses the coast at a pressure level near $610 \mathrm{hPa}$, which is somewhat higher by $\sim 100 \mathrm{hPa}$ than those of the ECMWF 3-D back trajectories starting at the inversion above the hook (Fig. 3). In the model, large $\mathrm{SO}_{2}$ and $\mathrm{CCN}$ concentrations extend up to $\sim 500 \mathrm{hPa}$ (Fig. 13c) and the hook of elevated $N_{\mathrm{d}}$ extends further west than the observed hook. This is consistent with the model simulating overly strong upward vertical transport over land, leading to CCN in the FT in the model that extends further north and west than the observed $N_{\mathrm{d}}$ suggests.

\subsection{Interpolation over 3-D trajectories}

Most chemical and aerosol fields interpolated over the 3-D trajectory described in Sect. 4.4 do not vary much during marine FT transport (not shown). However, Aitken-mode number concentrations decline from $\sim 800 \mathrm{~cm}^{-3}$ to $\sim 400 \mathrm{~cm}^{-3}$ over $12 \mathrm{~h}$ during the early part of the descent toward the MBL top, while there is minimal change in the accumulationmode concentration, suggesting coagulation of the relatively large number concentrations of the small $\sim 0.01 \mu \mathrm{m}$ particles in the plume. Using Brownian coagulation kernel estimates (Seinfeld and Pandis, 1998) we compute a similar loss of Aitken number concentration as modeled. Following this period, accumulation-mode, Aitken-mode, and CCN number concentrations remain steady until very near the inversion level. Additionally the $\mathrm{SO}_{2}$ concentration remains steady, as does sulfate mixing ratio, though once the trajectory is near the $\mathrm{MBL} \mathrm{SO}_{4}$ gradually increases by $40 \%$ due to aqueous phase processing of entrained and DMS-derived $\mathrm{SO}_{2}$. This indicates relatively simple advection without significant chemical/aerosol changes until entry into clouds. There is no evidence of strong nucleation events, significant aerosol size changes, or any other mechanism that would markedly change the $\mathrm{CCN}$ as a plume of polluted air transports over the marine SEP in the FT. 

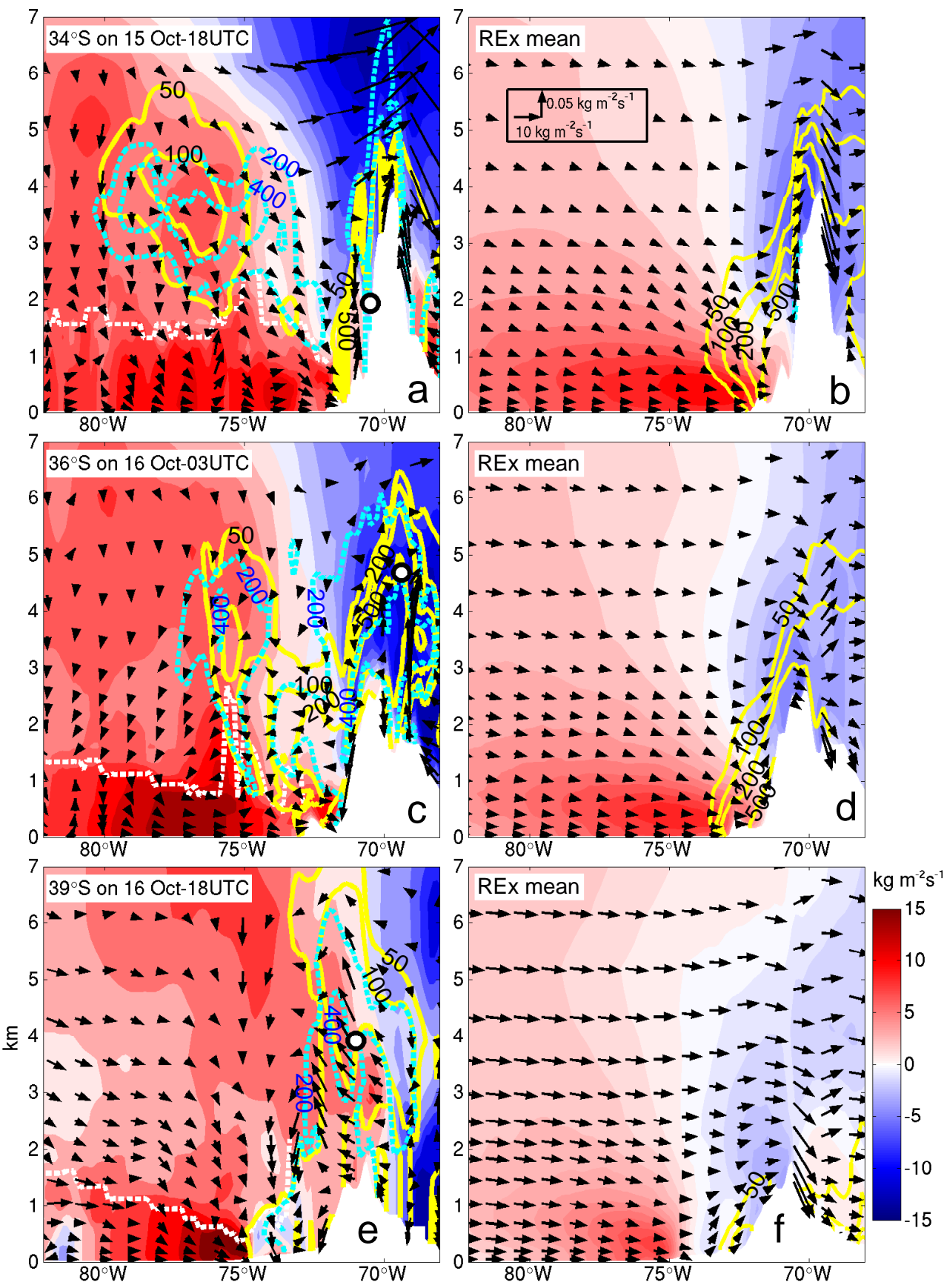

Fig. 13. WRF-Chem zonal transects at latitudes following a WRF-Chem 3-D trajectory (white circle markers here, following the trajectory marked with circle in Fig. 12) of winds (multiplied by density to give mass fluxes), CCN at $0.5 \%$ supersaturation (cyan dashed lines) at 200 and $400 \mathrm{~cm}^{-3}$ (numbers in blue), and $\mathrm{SO}_{2}$ concentrations (yellow lines) at 50, 100, 200, and 500 pptv (numbers in black). Filled colored contours show the magnitude of the meridional component of wind (positive is southerly flow), while vectors show zonal and vertical components. The white dashed line indicates an estimate of the inversion height. Left columns are interpolated snapshots at the time of the trajectory and right columns show REx mean properties at the same latitude.

\subsection{Sources of hook aerosols}

Neither DMS-derived $\mathrm{SO}_{4}$ nor long-range transport of species input via boundary conditions, both of which are present in the NoAnth simulation, cause hook formation (Fig. 9d). A model run without DMS (NoDMS) has lower $N_{\mathrm{d}}$ by $\sim 15 \%$ both in and outside the hook, but the NoDMS hook $N_{\mathrm{d}}$ peak occurs about 1-2 degrees "behind", 

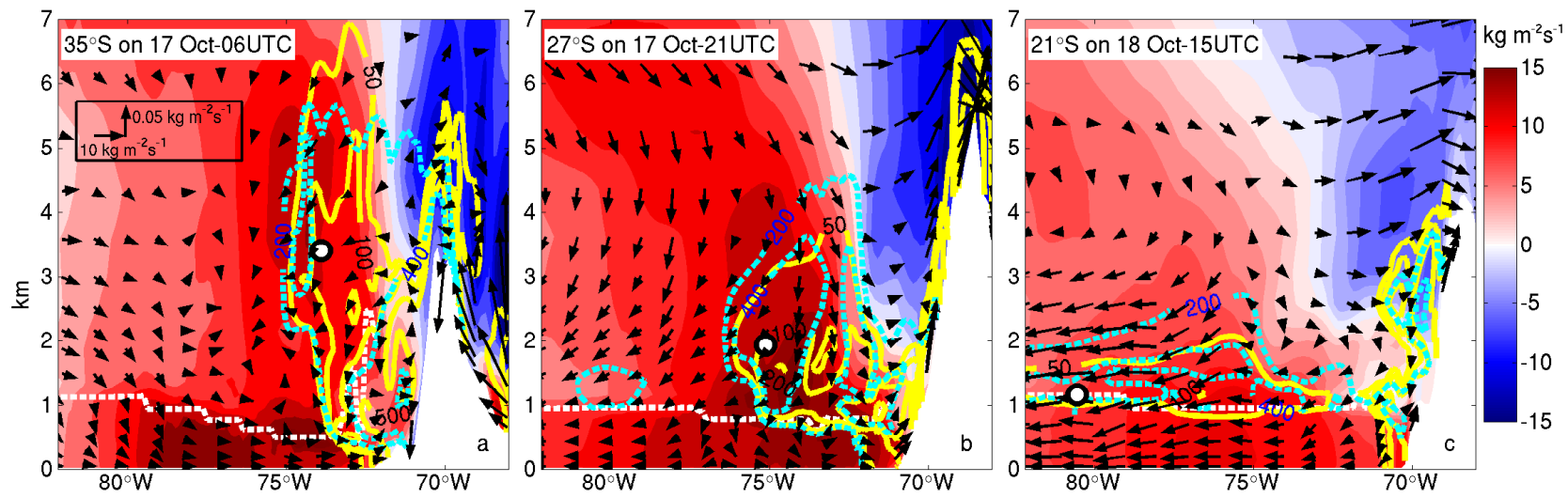

Fig. 14. Same as left column of Fig. 13 but for second half of the WRF-Chem 3-D trajectory (circle markers in Fig. 12) described in Sect. 4.4 as it advects northwest and subsides towards the boundary layer.

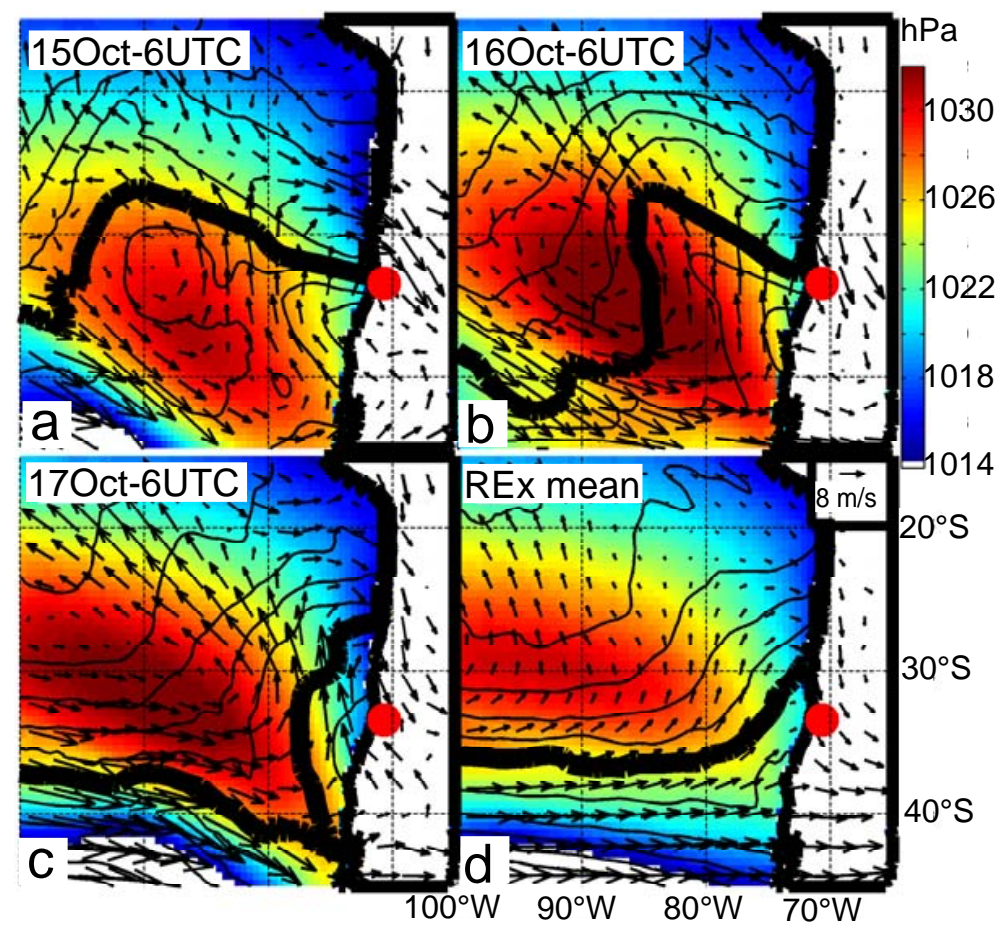

Fig. 15. WRF-Chem simulation surface pressure (colored contours), $500 \mathrm{hPa}$ heights (line contours) and $700 \mathrm{hPa}$ winds (arrows) at (a-c) in days preceding Hook1 at 06:00 UTC, and (d) REx mean conditions. The red circle marks Santiago. The bold $500 \mathrm{hPa}$ contour is $5350 \mathrm{~m}$ and the contour interval is $50 \mathrm{~m}$.

or southeast of, the Anth simulation hook (Fig. 9a, b). In the NoDMS run, both Aitken- and accumulation-mode number concentrations are very close to those in the Anth simulation, but the accumulation-mode particles are smaller, which shifts the MBL size distribution and reduces the number of particles activated. A binned aerosol scheme would probably be more appropriate than a modal scheme to investigate this further.

When emissions south of $31^{\circ} \mathrm{S}$ are excluded, no clear Hook1 forms (not shown). Emissions from the northern
Chilean smelters and volcanoes therefore do not appear to advect to the remote SEP (Twohy et al., 2012). In a simulation without anthropogenic emissions east of the Andes $\left(70^{\circ} \mathrm{W}\right.$ ) and south of $30^{\circ} \mathrm{S}$ (Fig. 9c), the hook is also shifted behind the Anth hook with smaller peak $N_{\mathrm{d}}$ magnitude, but the basic hook characteristics remain intact. The emissions east of the Andes are small compared to the Santiago region, but also advect offshore with the cyclonic flow and affect the hook shape, extent, and magnitude. These sensitivity studies clearly demonstrate that transport of anthropogenic aerosol 


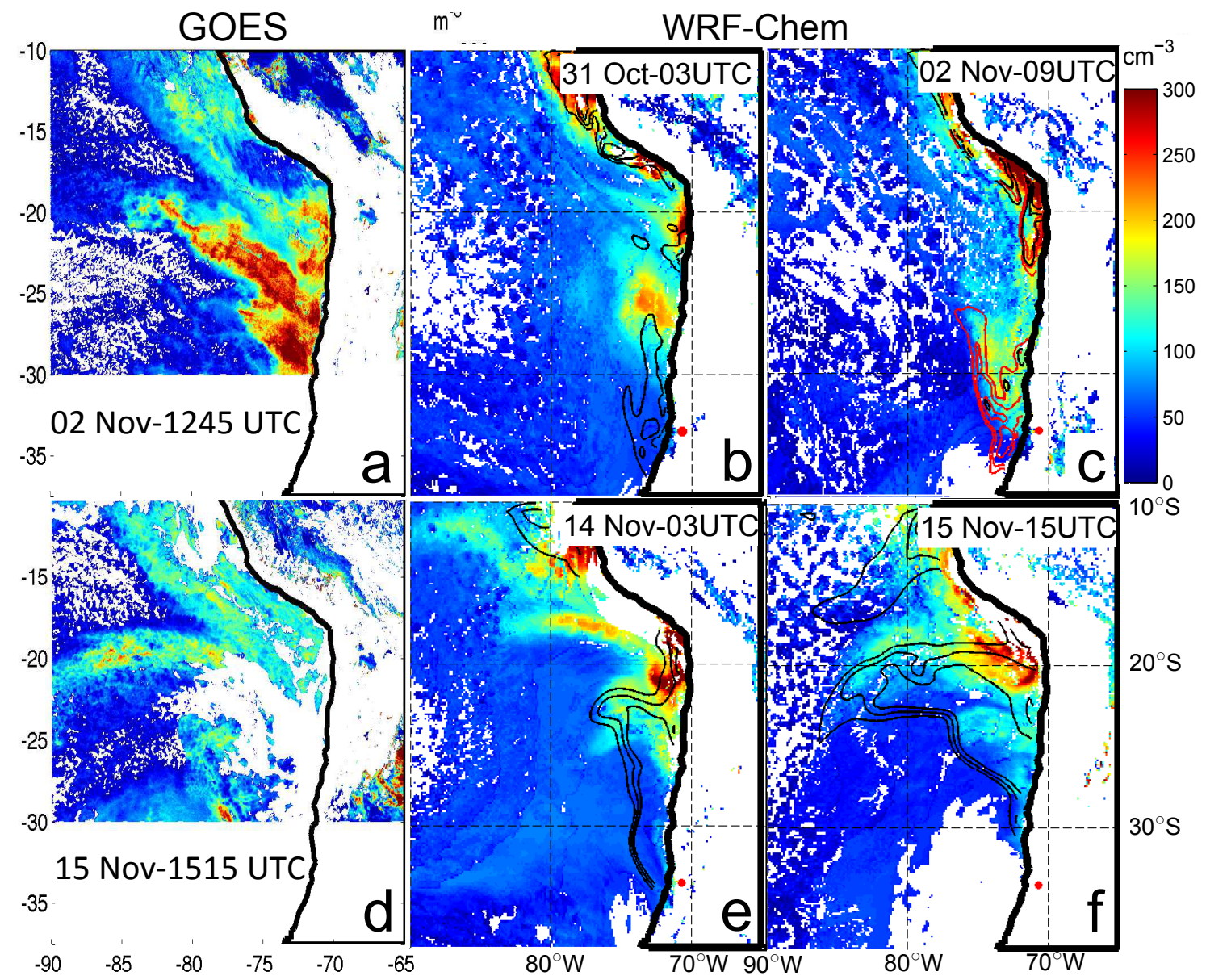

Fig. 16. GOES-derived $N_{\mathrm{d}}$ of Hook 2 on 2 November at 12:45 UTC in (a) and of Hook3 on 15 November at 15:15 UTC in (e), with model $N_{\mathrm{d}}$ snapshots on (b) 31 October at 03:00 UTC, (c) 2 November at 09:00 UTC (chosen because it demonstrates closer agreement with (a) than other times), (e) 14 November at 03:00 UTC, and (f) 15 November at 15:00 UTC. The red dot marks Santiago. Black contours are FT maximum CCN at $0.5 \%$ at 100,200 , and $400 \mathrm{~cm}^{-3}$. By (c) marine FT CCN is $<100 \mathrm{~cm}^{-3}$ near the region of large $N_{\mathrm{d}}$, so $\mathrm{SO}_{2}$ at 100,200 , and 400 pptv is also shown in red contours.

sources from the Santiago region is the dominant source of Hook1 $N_{\mathrm{d}}$ but the location and magnitude of the hook is sensitive to processes affecting the FT plume and the MBL $\mathrm{CCN}$.

\section{Other hooks}

Our analysis shows that are four key elements of the Hook1 event are (a) Santiago area emissions, (b) an initial southward and upward transport, (c) subsequent offshore flow, and (d) subsidence and entrainment. Two other pronounced hooks formed during REx. In this section we present observations and simulations of these cases, looking for these same elements. Unfortunately, WRF-Chem underestimates the offshore extent and magnitude of the observed $N_{\mathrm{d}}$ maximum in Hook3 and especially Hook2 (Fig. 16). However, in both of these cases, the model does simulate offshore flow of
Santiago-region emissions in the FT that subsides, entrains, and enhances $N_{\mathrm{d}}$ west of the region most impacted by coastal aerosols on average (Fig. 1).

\subsection{Hook 2: 2 November 2008}

Hook2, at its peak, is an extended region of high $N_{\mathrm{d}}$ cloud reaching from the Chilean coast between 24 and $30^{\circ} \mathrm{S}$ in a northwestward direction out to $20^{\circ} \mathrm{S}, 83^{\circ} \mathrm{W}$ on 2 November (Fig. 16a). ECMWF MBL 2-D back trajectories from the offshore tip of the hook trace a region of high- $N_{\mathrm{d}}$ clouds to near the coast (not shown), indicating that some pollution transport takes place within the MBL from coastal sources to the remote ocean, in contrast to Hook1. The MBL transition from the polluted hook to the clean conditions was sampled near $22^{\circ} \mathrm{S}, 80^{\circ} \mathrm{W}$ between 09:00 and 12:00 UTC on 2 November by the VOCALS C-130 flight RF08. Near the coast, $\mathrm{CCN}$ concentrations exceeding $500 \mathrm{~cm}^{-3}$ (at $\sigma=$ 
$0.5 \%)$ were measured in the FT along $20^{\circ} \mathrm{S}$, but much lower concentrations $\left(\sim 150-180 \mathrm{~cm}^{-3}\right)$ were measured further west along $20^{\circ} \mathrm{S}$, so in situ flight measurements do not coincide with large FT aerosol concentrations in the remote ocean that would support the polluted tongue.

WRF-Chem severely underestimates the hook $N_{\mathrm{d}}$ for this event (Fig. 16c), although a region of somewhat increased $N_{\mathrm{d}}$ extends from the Santiago region to $\sim 25^{\circ} \mathrm{S}, 75^{\circ} \mathrm{W}$. This region does not develop further over the remote ocean at later model times. This suggests the model is not correctly simulating the offshore advection of aerosol. There is offshore flow of FT air with $200 \mathrm{~cm}^{-3} \mathrm{CCN}$ on $30-31$ October (Fig. 16b) extending from south of Santiago. On the day of the hook, $\mathrm{FT} \mathrm{SO}_{2}$ concentrations reach 400 pptv along the western edge of the modeled region of elevated $N_{\mathrm{d}}$ region, but no substantial model FT source of $\mathrm{CCN}$ remains over the ocean (Fig. 16c). The simulated region of large $\mathrm{FT} \mathrm{SO}_{2}$ does not reach west of $77^{\circ} \mathrm{W}$ or north of $25^{\circ} \mathrm{S}$, consistent with the RF08 observations of a relatively unpolluted FT further to the northwest.

Figure 17 shows 3-D WRF-Chem back trajectories from the FT above the modeled region of elevated $N_{\mathrm{d}}$ seen in Fig. 16c. They indicate lofted air from south of Santiago subsiding towards the MBL (Fig. 17a). That higher concentrations of $\mathrm{FT} \mathrm{SO}_{2}$ but smaller number concentrations of $\mathrm{CCN}$ are transported offshore in the FT than in the Hook1 case indicates weaker nucleation processes prior to offshore advection and reduces the impact of the entrained plume on $N_{\mathrm{d}}$ (because entrained $\mathrm{SO}_{2}$ is more likely to add mass to existing aerosols rather than nucleate more particles in the MBL). Three possible reasons why WRF-Chem does not produce the distinct observed hook are the following: (1) excessive $\mathrm{CCN}$ loss rates within the MBL, which quickly remove $\mathrm{CCN}$ advected in the MBL from coastal pollution sources; (2) underestimated nucleation of new particles in the pollution plume that can subsequently serve as $\mathrm{CCN}$, which may prevent the FT aerosol plume from maintaining the offshore portion of the hook; and (3) modeling errors in the altitude, latitude, and/or magnitude of offshore flow of polluted air necessary for continental air to reach the remote ocean.

Like Hook1, a southeastward-shifted subtropical high behind an upper level trough both precede the observed hook, but the sea-level pressure anomaly is much weaker than in Hook 1 and the upper-level trough intersects the coastline further north. This causes a weaker event and a different hook shape, but nonetheless favors transport of pollution into the remote ocean.

\subsection{Hook 3: 15 November 2008}

Hook3, like Hook1, extends far offshore (Fig. 16d), as seen in the satellite retrieval chosen to overlap with VOCALS flight RF14 that sampled the hook out to $80^{\circ} \mathrm{W}$ near $20^{\circ} \mathrm{S}$ on 15 November between 15:00 and 20:00 UTC. A layer with mean $\mathrm{SO}_{2}$ concentrations of $550 \mathrm{ppt}$ was observed in the $\mathrm{FT}$ less than $100 \mathrm{~m}$ above cloud top at $80^{\circ} \mathrm{W}, 20-22^{\circ} \mathrm{S}$. The mean concentration of $\mathrm{CCN}$ at $\sigma=0.5 \%$ during this flight leg was $1100 \mathrm{~cm}^{-3}$, indicating an unusually polluted FT over the remote SEP.

The model produces a hook qualitatively similar to, but less extensive than, that observed (Fig. 16f). It captures a hook of large FT CCN concentrations (Fig. 16f), but the $\mathrm{CCN}$ concentration at $80^{\circ} \mathrm{W}$ is much smaller than measured. Again, model back trajectories indicate that much of the FT transport is composed of Santiago-region emissions (Fig. 17b). However, Fig. 17b also shows that some model 3-D back trajectories from the hook correspond to offshore flow at $27-28^{\circ} \mathrm{S}$ in the FT, so sources north of Santiago may also contribute to the polluted air over the remote ocean. From both sources, high concentrations of $\mathrm{SO}_{2}$ and $\mathrm{CCN}$ advect upward and southward, then offshore, but do not reach as far south as they do in Hook1. 2-D MBL model back trajectories encounter the coast just to the south of the Santiago region, so MBL transport cannot be ruled out as a hook source of $\mathrm{CCN}$ in this case. However, over the four days of transport from the coast to the remote ocean, aerosol number loss processes such as precipitation and cloud processing reduce the likelihood of it being the sole source of hook CCN.

As with the other hook cases, a high-pressure system shifted southward and eastward from its climatological mean occurs. The high stays close the coast south of Santiago for several days, contributing to Hook3 and subsequently a much stronger hook on 19 November. The upper level flow is not characterized by the same system noted in Hook1 and Hook2, but a near-shore trough does allow for upper-level offshore flow. Polluted FT plumes contributing to Hook3 travel north of $24^{\circ} \mathrm{S}$ before westward advection past $75^{\circ} \mathrm{W}$ (Fig. 17b), far enough away from the southward-shifted subtropical high to experience weaker subsidence than average. Thus, FT polluted layers that have not yet been entrained into the MBL are observed on RF14 lying above the remote ocean cloud. In the model a plume of high $\mathrm{CCN}$ concentration at $2 \mathrm{~km}$ altitude at $28^{\circ} \mathrm{S}, 72.5^{\circ} \mathrm{W}$ at 06:00 UTC on 14 November does not intersect the MBL until it reaches $22^{\circ} \mathrm{S}, 82^{\circ} \mathrm{W}$ on 15 November at 12:00 UTC. This took $12 \mathrm{~h}$ longer to subside to the inversion and traveled about 3.5 degrees longitude further than the Hook1 trajectory (cf. Fig. 14b, c) subsidence from near $2 \mathrm{~km}$ to the inversion (over a similar latitude change). This weaker subsidence allows for greater westward FT transport than other situations of offshore flow at $2 \mathrm{~km}$. Nevertheless, Hook 1 extends further west than Hook3 in the model because of the deeper layer of FT offshore transport.

\subsection{Commonalities between hooks}

Although the model does not reproduce all three major observed $N_{\mathrm{d}}$ hooks in the REx period well, it does simulate FT offshore flow of polluted plumes of $\mathrm{CCN} / \mathrm{SO}_{2}$ from the Santiago region and as far south as $35.5^{\circ} \mathrm{S}$ in the model. The model does not simulate FT offshore flow this far south at 


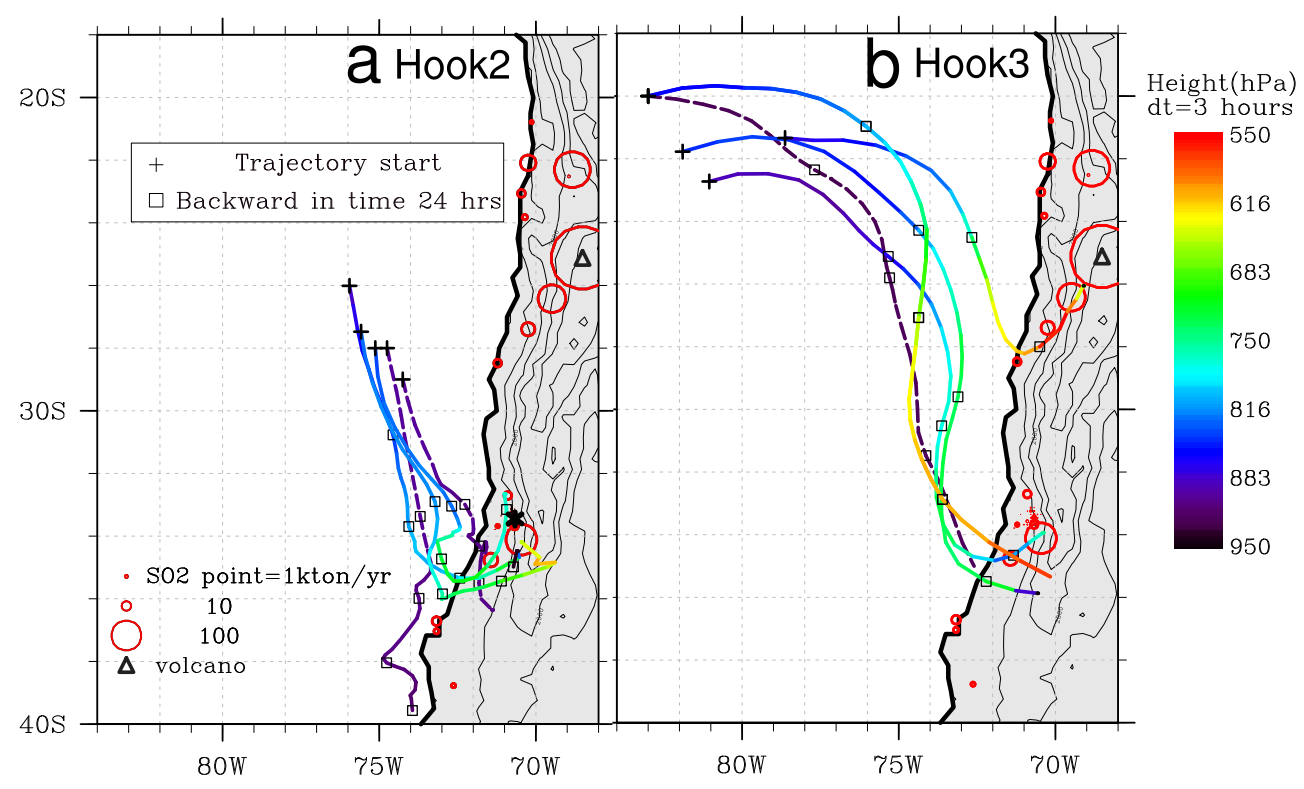

Fig. 17. WRF-Chem 3-D back trajectories (solid) initialized from points in the model level above the inversion within region of large $\mathrm{SO}_{2}$ concentrations and 2-D back trajectories (dashed) in the MBL (two model levels below the inversion) at points of large model $N_{\mathrm{d}}$. Trajectories are initialized on (a) 2 November at 09:00 UTC corresponding to the model Hook2 in Fig. 16c, and (b) 15 November at 15:00 UTC corresponding to the model Hook3 in Fig. 16f. Square markers indicate $24 \mathrm{~h}$ intervals, and red circles are $\mathrm{SO}_{2} \mathrm{point}$ sources as in Fig. 3.

any time during REx besides the $2-3$ days preceding the three hook cases. Hence, it suggests that FT flow off the Chilean coast near or just south of Santiago is an important component of hook formation during REx. Emissions at other latitudes and altitudes may contribute to the observed hook in some cases, but Santiago-region emissions are key. Santiagoarea pollution plumes experience some lofting (to altitudes of 3-6 km) and southward transport in all three cases, especially Hook1, before being advected offshore, after which they subside and are entrained into the MBL, contributing to the hook feature in $N_{\mathrm{d}}$. All three hooks also have evidence of MBL transport of regions of elevated $N_{\mathrm{d}}$ after the FT source has been depleted. Although in some cases direct MBL transport from coastal regions may substantially contribute to hook CCN (especially Hook2), entrainment appears key to supporting offshore high $N_{\mathrm{d}}$. In summary, remote ocean $N_{\mathrm{d}}$ hooks appear strongly linked to FT transport of Santiago-region emissions, though more cases would need to be studied to gain absolute confidence in this association and to ascertain if MBL transport has a negligible effect on remote $N_{\mathrm{d}}$.

\section{Conclusions}

Periodic free-tropospheric transport of anthropogenic emissions to the typically stratocumulus-dominated pristine SEP remote ocean produces strong AIEs and a large source of cloud droplet concentration $\left(N_{\mathrm{d}}\right)$ variability. Stratocumulus $N_{\mathrm{d}}$ variability over the remote SEP is modulated by the passage of hooks - narrow bands of enhanced $N_{\mathrm{d}}$ (typically $>100 \mathrm{~cm}^{-3}$ ) extending from close to the coast for up to $1500 \mathrm{~km}$ offshore. The mean MBL accumulation-mode number concentration was measured by VOCALS to be $\sim 150 \mathrm{~cm}^{-3}$ in the MBL over the remote ocean west of $80^{\circ} \mathrm{W}$ along $20^{\circ} \mathrm{S}$ (Allen et al., 2011), with mean $N_{\mathrm{d}}$ values below $100 \mathrm{~cm}^{-3}$. To achieve the $250-350 \mathrm{~cm}^{-3} N_{\mathrm{d}} \mathrm{ob}-$ served in hooks without a supply of additional CCN would require unrealistically large supersaturation to activate all of the accumulation-mode and a substantial number of small Aitken-mode particles. Within a developing hook, supersaturation changes driven by precipitation impacts on TKE do appear to influence the magnitude of the $N_{\mathrm{d}}$ increase substantially, as shown in this paper, but this is a secondary effect compared with the introduction of high $\mathrm{CCN}$ concentrations in the remote MBL.

In this study, the WRF-Chem model is run for the monthlong VOCALS-REx period (15 October to 16 November 2008), during which three major hook events were identified. The strongest of the three is reproduced quite faithfully by the model (except for a significant timing error) and is used to investigate the formation, evolution, decay, and possible radiative impacts of a hook. Trajectory analysis indicates the aerosols responsible for this feature were primarily transported in the lower free troposphere above the inversion from south of Santiago before entraining into the MBL and 
enhancing cloud droplet concentration $\sim 1000 \mathrm{~km}$ offshore to levels more typical of the near-shore polluted region. This mechanism likely explains many of the hook features observed over the SEP, and similar features may be occurring over other subtropical eastern ocean regions. Advection of coastal pollution within the MBL appears to be more important for one of the other two hook events, though it is unlikely facing loss processes of precipitation and dilution that MBL advection can lead to remote ocean hooks without some additional FT support supplying CCN to the MBL along the way. Oceanic DMS emissions have noticeable secondary effects on simulated hooks. Differences between the observed hooks and their simulated counterparts suggest that the detailed location and strength of hooks is sensitive to various possible sources of error, including subtle differences in the wind field and vertical mixing, especially on the slopes of the Andes, the assumed emissions, and both the free-tropospheric and boundary layer processing of aerosol.

The first hook event experiences a significant increase in $N_{\mathrm{d}}$ over the remote ocean that cannot be explained by MBL advection, and model results indicate entrainment of FT aerosols is responsible. Albedo at the peak of the hook is larger than a simulation without anthropogenic aerosols, which is due largely to the Twomey effect, though secondary AIEs enhance this the Twomey effect and contribute 30$50 \%$ of the net albedo change. Albedo also increases during hook development primarily due to aerosol changes, but an increase in stability and weakening subsidence associated with the coincident meteorology is also noted in the simulation without anthropogenic aerosols and explains part of the albedo change.

Synoptic meteorological conditions and their interactions with the Andes topography are important to the FT CCN transport that leads to hook formation. Subsidence and the increase in MBL depth offshore often limit the westward reach of anthropogenic aerosols in the FT, so high concentrations of $\mathrm{CCN}$ in the remote FT must originate from significant lofting up the Andes prior to offshore flow or weak subsidence during offshore transport. However, the required westward flow is associated with the north end of the subtropical high and does not extend to heights of more than 5-6 km at most. Other meteorological scenarios may lead to offshore transport, but the ones during REx all coincided with a southeastward shift of the subtropical high associated with an upper-tropospheric trough approaching the Chilean coast from the west, causing changes to the normal direction of transport (Rahn and Garreaud, 2010a). Whether the transport is in the FT or the MBL, hook events require meteorologically anomalous offshore flow driven by changes in the strength and location of the subtropical high and a method to preserve or even enhance high $\mathrm{CCN}$ concentrations in the MBL during passage to the remote region.

Although there is general agreement between the observations and model for strong hook events, the model fails to match exactly the timing and extent of any of the hook fea- tures studied here. Because they affect the variability of $N_{\mathrm{d}}$ and therefore AIEs over the remote ocean and are so difficult to reproduce with a model, hooks represent a significant challenge in quantifying regional AIEs. The difficulty simulating them, even with a regional model with relatively high resolution, reflects the very precise sequence of meteorological conditions that must occur for these narrow bands of elevated offshore transport to bring aerosols to the right place at the right time. In addition, to capture the impact of a hook on radiation, the model must accurately represent the aerosol processing within the MBL that adds aerosol mass from DMSproduced $\mathrm{SO}_{2}$, in addition to turbulent and activation processes within stratocumulus. Correctly capturing and quantifying the variability in AIEs thus represents a formidable challenge. Transport of anthropogenic aerosols in the FT and resulting hook features through entrainment into the MBL likely contributes significantly to the albedo variability over the remote SEP, so overcoming the modeling challenges is important.

\section{Appendix A}

\section{Trajectories}

Trajectories are computed by solving the equation

$\mathrm{d} \boldsymbol{X} / \mathrm{d} t=\boldsymbol{v}(\boldsymbol{X}(t), t)$

where $t$ is time, $\boldsymbol{X}$ the position vector, and $\boldsymbol{v}$ the wind vector in three dimensions. This equation is integrated over time using the iterative Petterssen (1940) scheme.

$$
\begin{aligned}
& \boldsymbol{X}\left(t_{\mathrm{i}}\right)=\boldsymbol{X}\left(t_{i-1}\right)+\mathrm{d} t / 2 \\
& \times\left\{\boldsymbol{v}\left(\boldsymbol{X}\left(t_{i-1}\right), t_{i-1}\right)+\boldsymbol{v}\left(\boldsymbol{X}\left(t_{\mathrm{i}}\right), t_{\mathrm{i}}\right)\right\}
\end{aligned}
$$

$\boldsymbol{X}_{\text {init }}\left(t_{\mathrm{i}}\right)$ is initially approximated as $\boldsymbol{X}\left(t_{i-1}\right)+$ $\boldsymbol{v}\left(\boldsymbol{X}\left(t_{i-1}\right), t_{i-1}\right) \cdot \mathrm{d} t$. Then $\boldsymbol{v}\left(\boldsymbol{X}_{\text {init }}\left(t_{\mathrm{i}}\right), t_{\mathrm{i}}\right)$ is interpolated to compute a new $\boldsymbol{X}\left(t_{\mathrm{i}}\right)$ from Eq. (A2). If $\boldsymbol{X}\left(t_{\mathrm{i}}\right)-\boldsymbol{X}_{\text {init }}\left(t_{\mathrm{i}}\right)$ is below a threshold error, the iteration stops, otherwise $\boldsymbol{X}\left(t_{\mathrm{i}}\right)$ becomes the new $\boldsymbol{X}_{\text {init }}\left(t_{\mathrm{i}}\right)$ and the calculation continues until $\boldsymbol{X}\left(t_{\mathrm{i}}\right)-\boldsymbol{X}_{\text {init }}\left(t_{\mathrm{i}}\right)$ is sufficiently small. Three-dimensional ECMWF trajectories are computed using its hybrid sigma pressure coordinates, while the WRF-Chem trajectories are based on the terrain following eta coordinate. Twodimensional trajectories are computed by setting vertical velocity to zero. Trajectories are computed both forward and backward in time.

Two-dimensional MBL model trajectories start from two model levels below the inversion, which is around 900$950 \mathrm{mb}$, and 2-D ECMWF trajectories start at $950 \mathrm{mb}$. Trajectories remain at a fixed eta or hybrid sigma pressure level, and given the deepening of the boundary layer in the SEP east-west direction, trajectories forward in time are further below the inversion than earlier along the trajectory. Due to the relative homogeneity (little shear) of winds within the 
boundary layer, these trajectories track the hook (model or observed) well.

Over the ocean, computed trajectories are assumed to capture the direction and magnitude of transport because of the strong meteorological forcing of the subtropical high and relative homogeneity of the MBL winds. Near the Andes the land-sea thermal contrast, diurnal land heating cycle, and mountain effects complicate the wind fields. Enough variability occurs within the $6 \mathrm{~h}$ timesteps of the ECMWF that confidence in the path of the ECMWF trajectories over land is greatly reduced. Model trajectories computed at $3 \mathrm{~h}$ intervals are subject to similar time resolution errors, but in some cases follow plumes of high CCN quite well (Figs. 13 and 14).

Over short periods of time an idealized parcel will be representative of air motion (Stohl et al., 1995). The length of time that trajectories continue to represent bulk transport of air is a limiting factor in using trajectory analysis. Sources of trajectory errors include the length of the timestep, wind field errors due to subgrid variability not captured by interpolation, and wind gradient errors (Riddle et al., 2006).

Acknowledgements. The authors thank Tony Clarke, David Covert, Daniel Grosvenor, and Joel Thornton for discussions and guidance. MODIS data were obtained from the NASA Goddard Land Processes data archive. The authors also thank Patrick Minnis and his research group for making GOES-derived cloud properties available. NCEP reanalysis data were obtained from NCEP Climate Diagnostics Center. VOCALS flight data were provided by NCAR/EOL under sponsorship of the National Science Foundation. http://data.eol.ucar.edu/.

Edited by: C. R. Mechoso

\section{References}

Abdul-Razzak, H. and Ghan, S. J.: A parameterization of aerosol activation 2. Multiple aerosol types, J. Geophys. Res.-Atmos., 105, 6837-6844, 2000.

Ackerman, A. S., Kirkpatrick, M. P., Stevens, D. E., and Toon, O. B.: The impact of humidity above stratiform clouds on indirect aerosol climate forcing, Nature, 432, 1014-1017, doi:10.1038/nature03174, 2004.

Ackermann, I. J., Hass, H., Memmesheimer, M., Ebel, A., Binkowski, F. S., and Shankar, U.: Modal aerosol dynamics model for Europe: development and first applications, Atmos. Environ., 32, 2981-2999, doi:10.1016/S1352-2310(98)00006-5, 1998.

Albrecht, B. A., Fairall, C. W., Thomson, D. W., White, A. B., Snider, J. B., and Schubert, W. H.: Surface based remote sensing of the observed and the Adiabatic liquid water content of stratocumulus clouds, Geophys. Res. Lett., 17, 89-92, doi:10.1029/GL017i001p00089, 1990.

Allen, G., Coe, H., Clarke, A., Bretherton, C., Wood, R., Abel, S. J., Barrett, P., Brown, P., George, R., Freitag, S., McNaughton, C.,
Howell, S., Shank, L., Kapustin, V., Brekhovskikh, V., Kleinman, L., Lee, Y.-N., Springston, S., Toniazzo, T., Krejci, R., Fochesatto, J., Shaw, G., Krecl, P., Brooks, B., McMeeking, G., Bower, K. N., Williams, P. I., Crosier, J., Crawford, I., Connolly, P., Allan, J. D., Covert, D., Bandy, A. R., Russell, L. M., Trembath, J., Bart, M., McQuaid, J. B., Wang, J., and Chand, D.: South East Pacific atmospheric composition and variability sampled along $20^{\circ} \mathrm{S}$ during VOCALS-REx, Atmos. Chem. Phys., 11, 5237-5262, doi:10.5194/acp-11-5237-2011, 2011.

Bandy, A. R., Thornton, D. C., Tu, F. H., Blomquist, B. W., Nadler, W., Mitchell, G. M., and Lenschow, D. H.: Determination of the vertical flux of dimethyl sulfide by eddy correlation and atmospheric pressure ionization mass spectrometry (APIMS), J. Geophys. Res.-Atmos., 107, 4743, doi:10.1029/2002JD002472, 2002.

Bennartz, R.: Global assessment of marine boundary layer cloud droplet number concentration from satellite, J. Geophys. Res.Atmos., 112, D02201, doi:10.1029/2006JD007547, 2007.

Bretherton, C. S. and Park, S.: A new moist turbulence parameterization in the community atmosphere model, J. Climate, 22, 3422-3448, doi:10.1175/2008JCLI2556.1, 2009.

Bretherton, C. S., Blossey, P. N., and Uchida, J.: Cloud droplet sedimentation, entrainment efficiency, and subtropical stratocumulus albedo, Geophys. Res. Lett., 34, L03813, doi:10.1029/2006GL027648, 2007.

Bretherton, C. S., Wood, R., George, R. C., Leon, D., Allen, G., and Zheng, X.: Southeast Pacific stratocumulus clouds, precipitation and boundary layer structure sampled along $20^{\circ} \mathrm{S}$ during VOCALS-REx, Atmos. Chem. Phys., 10, 10639-10654, doi:10.5194/acp-10-10639-2010, 2010.

Carn, S. A., Krueger, A. J., Krotkov, N. A., Yang, K., and Levelt, P. F.: Sulfur dioxide emissions from Peruvian copper smelters detected by the ozone monitoring instrument, Geophys. Res. Lett., 34, L09801, doi:10.1029/2006GL029020, 2007.

Chang, J. S., Binkowski, F., Seaman, N., McHenry, J., Samson, P., Stockwell, W., Walcek, C., Madronich, S., Middleton, P., Pleim, J., and Lansford, H.: The regional acid deposition model and engineering model, in: Acidic Deposition: State of Science and Technology, National Acid Precipitation Assessment Program, Washington DC., 25-78, 1990.

Chapman, E. G., Gustafson Jr., W. I., Easter, R. C., Barnard, J. C., Ghan, S. J., Pekour, M. S., and Fast, J. D.: Coupling aerosolcloud-radiative processes in the WRF-Chem model: Investigating the radiative impact of elevated point sources, Atmos. Chem. Phys., 9, 945-964, doi:10.5194/acp-9-945-2009, 2009.

Chou, M. D., Suarez, M. J., Ho, C. H., Yan, M. M. H., and Lee, K. T.: Parameterizations for cloud overlapping and shortwave single-scattering properties for use in general circulation and cloud ensemble models, J. Climate, 11, 202-214, doi:10.1175/1520-0442(1998)011<0202:PFCOAS > 2.0.CO;2, 1998.

Clarke, A. D., and Kapustin, V.: Hemispheric aerosol vertical profiles: anthropogenic impacts on optical depth and cloud nuclei, Science, 329(5998), 1488-1492, doi:10.1126/science.1188838, 2010.

Clarke, A. D., Uehara, T., and Porter, J. N.: Lagrangian evolution of an aerosol column during the Atlantic Stratocumulus Transition Experiment, J. Geophys. Res., 101, 4351-4362, doi:10.1029/95JD02612,1996. 
Clarke, A. D., Varner, F., Eisele, F., Tanner, R., Maudlin, L., and Litchy, M.: Particle production in the remote marine atmosophere: Cloud outflow and subsidence during ACE-1, J. Geophys. Res., 103, 16397-16409, doi:10.1029/97JD02987, 1998.

Clarke, A. D., Kapustin, V., Collins, W., Rasch, P., Moor, K., Howell, S., and Fuelberg, H.: Dust and Pollution Transport on Global Scales: Aerosol Measurements and Model Predictions, J. Geophys. Res., 32555-32569, 106, D23, doi:10.1029/2000JD900842,2001.

Clarke, A. D., Freitag, S., Brekhovskikh, V., Campos, T., Snider, J. R., Kasputin, V., Howell, S., and Shank, L.: Combustion aerosol, entrainment, and clouds in the VOCALS region, CLIVAR Exchanges, 15, 2, 2010a.

Clarke, A. D., Snider, J. R., Campos, T., Freitag, S., Brekhovskikh, V., Howell, S., Shank, L., Kasputin, V., and McNaughton, C.: Combustion aerosol, entrainment, and clouds in the VOCALS region, The 13th Conference on Cloud Physics, Portland, Oregon, 1 July 2010, Paper -9.2, 2010 b.

Clarke, A. D., Freitag, S., Simpson, R. M. C., Hudson, J. G., Howell, S. G., Brekhovskikh, V. L., Campos, T., Kapustin, V. N., and Zhou, J.: Free Troposphere as the dominant Source of CCN in the Equatorial Pacific Boundary Layer: Long-Range Transport and Teleconnections,Atmos. Chem. Phys. Discuss., 13, 1279-1326, doi:10.5194/acpd-13-1279-2013,2013.

Emmons, L. K., Walters, S., Hess, P. G., Lamarque, J.-F., Pfister, G. G., Fillmore, D., Granier, C., Guenther, A., Kinnison, D., Laepple, T., Orlando, J., Tie, X., Tyndall, G., Wiedinmyer, C., Baughcum, S. L., and Kloster, S.: Description and evaluation of the Model for Ozone and Related chemical Tracers, version 4 (MOZART-4), Geosci. Model Dev., 3, 43-67, doi:10.5194/gmd3-43-2010, 2010.

Fahey, K. M. and Pandis, S. N.: Optimizing model performance: variable size resolution in cloud chemistry modeling, Atmos. Environ., 35, 4471-4478, doi:10.1016/S1352-2310(01)00224-2, 2001.

Fast, J. D., Gustafson Jr., W. I., Easter, R. C., Zaveri, R. A., Barnard, J. C., Chapman, E. G., Grell, G. A., and Peckham, S. E.: Evolution of ozone, particulates, and aerosol direct radiative forcing in the vicinity of Houston using a fully coupled meteorology-chemistry-aerosol model, J. Geophys. Res.-Atmos., 111, D21305, doi:10.1029/2005JD006721, 2006.

George, R. C. and Wood, R.: Subseasonal variability of low cloud radiative properties over the southeast Pacific Ocean, Atmos. Chem. Phys., 10, 4047-4063, doi:10.5194/acp-10-4047-2010, 2010.

Gettelman, A., Liu, X., Ghan, S. J., Morrison, H., Park, S., Conley, A. J., Klein, S. A., Boyle, J., Mitchell, D. L., and Li, J. L. F.: Global simulations of ice nucleation and ice supersaturation with an improved cloud scheme in the community atmosphere model, J. Geophys. Res.-Atmos., 115, D18216, doi:10.1029/2009JD013797, 2010.

Gong, S. L., Barrie, L. A., and Blanchet, J. P.: Modeling sea-salt aerosols in the atmosphere 1. Model development, J. Geophys. Res.-Atmos., 102, 3805-3818, doi:10.1029/96jd02953, 1997.

Grell, G. A., Peckham, S. E., Schmitz, R., McKeen, S. A., Frost, G., Skamarock, W. C., and Eder, B.: Fully coupled "online" chemistry within the WRF model, Atmos. Environ., 39, 6957-6975, doi:10.1016/j.atmosenv.2005.04.027, 2005.
Gustafson Jr., W. I., Chapman, E. G., Ghan, S. J., Easter, R. C., and Fast, J. D.: Impact on modeled cloud characteristics due to simplified treatment of uniform cloud condensation nuclei during NEAQS 2004, Geophys. Res. Lett., 34, L19809, doi:10.1029/2007GL030021, 2007.

Huneeus, N., Gallardo, L., and Rutllant, J. A.: Offshore transport episodes of anthropogenic sulfur in northern Chile: potential impact on the stratocumulus cloud deck, Geophys. Res. Lett., 33, L19819, doi:10.1029/2006GL026921, 2006.

Klein, S. A. and Hartmann, D. L.: The seasonal cycle of low stratiform clouds, J. Climate, 6, 1587-1606, doi:10.1175/15200442(1993)006<1587:TSCOLS > 2.0.CO;2, 1993.

Lohmann, U. and Feichter, J.: Global indirect aerosol effects: a review, Atmos. Chem. Phys., 5, 715-737, doi:10.5194/acp-5-7152005, 2005.

Mena-Carrasco, M., Ruiz, P., Stambuk, A., Stambuk, L., Granifo, R., and Jerardino, M.: Antecedentes para la Revision de las Normas Primarias de Calidad de Aire para Dioxido de Azufre, Monoxido de Carbono, Ozono, Dioxido de Nitrogeno, Santiago, Chile, 2010.

Morrison, H. and Pinto, J. O.: Mesoscale modeling of springtime Arctic mixed-phase stratiform clouds using a new twomoment bulk microphysics scheme, J. Atmos. Sci., 62, 36833704, doi:10.1175/JAS3564.1, 2005.

Muñoz, R. C. and Alcafuz, R. I.: Variability of urban aerosols over Santiago, Chile: comparison of surface $\mathrm{PM}_{10}$ concentrations and remote sensing with ceilometer and lidar, Aerosol Air Qual. Res., 12, 8-19, doi:10.4209/aaqr.2011.08.0133, 2012.

Nightingale, P. D., Malin, G., Law, C. S., Watson, A. J., Liss, P. S., Liddicoat, M. I., Boutin, J., and Upstill-Goddard, R. C.: In situ evaluation of air-sea gas exchange parameterizations using novel conservative and volatile tracers, Global Biogeochem. Cy., 14, 373-387, doi:10.1029/1999GB900091, 2000.

Painemal, D., Minnis, P., Ayers, J. K., and O'Neill, L.: GOES-10 microphysical retrievals in marine warm clouds: multi-instrument validation and daytime cycle over the southeast Pacific, J. Geophys. Res.-Atmos., 117, D19212, doi:10.1029/2012JD017822, 2012.

Penner, J. E., Andreae, M., Annegarn, H., Barrie, L., Feichter, J., Hegg, D., Jayaraman, A., Leaitch, R., Murphy, D., Nganga, J., and Pitari, G.: Aerosols, their direct and indirect effects, in: Climate Change 2001: The Scientific Basis. Report to Intergovernmental Panel on Climate Change from the Scientific Assessment Working Group (WGI), edited by: Houghton, J. T., Ding, Y., Griggs, D. J., Noguer, M., Van der Linden, P. J., Dai, X., Maskell, K., and Johnson, C. A., Cambridge University Press, Cambridge, UK, 289-416, 2001.

Platnick, S. and Twomey, S.: Determining the susceptibility of cloud albedo to changes in droplet concentrations with the advanced very high resolution radiometer, J. Appl. Meteorol., 33, 334-347, doi:10.1175/15200450(1994)033<0334:DTSOCA > 2.0.CO;2, 1994.

Rahn, D. A. and Garreaud, R.: Marine boundary layer over the subtropical southeast Pacific during VOCALS-REx - Part 1: Mean structure and diurnal cycle, Atmos. Chem. Phys., 10, 4491-4506, doi:10.5194/acp-10-4491-2010, 2010a.

Rahn, D. A. and Garreaud, R.: Marine boundary layer over the subtropical southeast Pacific during VOCALS-REx Part 2: Synoptic variability, Atmos. Chem. Phys., 10, 4507-4519, 
doi:10.5194/acp-10-4507-2010, $2010 \mathrm{~b}$.

Randall, D., Wood, R., Bony, S., Colman, R., Fichefet, T., Fyfe, J., Kattsov, V., Pitman, A., Shukla, J., Srinivasan, J., Stouffer, R., Sumi, A., and Taylor, K.: Climate models and their evaluation, in: Climate Change 2007: The Physical Science Basis. Contribution of Working Group I to the Fourth Assessment Report of the Intergovernmental Panel on Climate Change, Cambridge University Press, Cambridge, UK and New York, NY, USA, 153-185, 2007.

Riddle, E. E., Voss, P. B., Stohl, A., Holcomb, D., Maczka, D., Washburn, K., and Talbot, R. W.: Trajectory model validation using newly developed altitude-controlled balloons during the International Consortium for Atmospheric Research on Transport and Transformations 2004 campaign, J. Geophys. Res.-Atmos., 111, D23S57, doi:10.1029/2006JD007456, 2006.

Saide, P. E., Spak, S. N., Carmichael, G. R., Mena-Carrasco, M. A., Yang, Q., Howell, S., Leon, D. C., Snider, J. R., Bandy, A. R., Collett, J. L., Benedict, K. B., de Szoeke, S. P., Hawkins, L. N., Allen, G., Crawford, I., Crosier, J., and Springston, S. R.: Evaluating WRF-Chem aerosol indirect effects in Southeast Pacific marine stratocumulus during VOCALS-REx, Atmos. Chem. Phys., 12, 3045-3064, doi:10.5194/acp-12-3045-2012, 2012.

Schell, B., Ackermann, I. J., Hass, H., Binkowski, F. S., and Ebel, A.: Modeling the formation of secondary organic aerosol within a comprehensive air quality model system, J. Geophys. Res.-Atmos., 106, 28275-28293, doi:10.1029/2001JD000384, 2001

Schüller, M., Estrada, A., and Bringezu, S.: Mapping environmental performance of international raw material production flows: a comparative case study for the copper industry of Chile and Germany, Miner. Energ., 23, 29-45, 2008.

Schwartz, S. E., Harshvardhan, and Benkovitz, C. M.: Influence of anthropogenic aerosol on cloud optical depth and albedo shown by satellite measurements and chemical transport modeling, P. Natl. Acad. Sci. USA, 99, 1784-1789, doi:10.1073/pnas.261712099, 2002.

Seinfeld, J. and Pandis, S.: Atmospheric Chemistry and Physics: From Air Pollution to Climate Change, 1st edn., J. Wiley, New York, 1998.

Shank, L. M., Howell, S., Clarke, A. D., Freitag, S., Brekhovskikh, V., Kapustin, V., McNaughton, C., Campos, T., and Wood, R.: Organic matter and non-refractory aerosol over the remote Southeast Pacific: oceanic and combustion sources, Atmos. Chem. Phys., 12, 557-576, doi:10.5194/acp-12-5572012, 2012.

Snider, J. R., Petters, M. D., Wechsler, P., and Liu, P. S. K.: Supersaturation in the Wyoming $\mathrm{CCN}$ instrument, J. Atmos. Ocean. Tech., 23, 1323-1339, doi:10.1175/JTECH1916.1, 2006.

Spak, S. N., Mena, M. A., and Carmichael, M. A.: Atmospheric transport of anthropogenic oxidized sulfur over the Southeast Pacific during VOCALS REx, CLIVAR Exchanges, 15, 2, 2010.

Stockwell, W. R., Middleton, P., Chang, J. S., and Tang, X. Y.: The second generation regional acid deposition model chemical mechanism for regional air quality modeling, J. Geophys. Res.Atmos., 95, 16343-16367, doi:10.1029/JD095iD10p16343, 1990.

Stevens, B., Cotton, W. R., Feingold, G., and Moeng, C. H.: Large-Eddy Simulations of Strongly Precipitating, Shallow Stratocumulus-Topped Boundary Lay- ers, J. Atmos. Sci., 55, 3616-3638, doi:10.1175/15200469(1998)055<3616:LESOSP > 2.0.CO;2, 1998.

Stohl, A., Wotawa, G., Seibert, P., and Krompkolb, H.: Interpolation errors in wind fields as a function of spatial and temporal resolution and their impact on different types of kinematic trajectories, J. Appl. Meteorol., 34, 2149-2165, doi:10.1175/15200450(1995)034<2149:IEIWFA>2.0.CO;2, 1995.

Thornton, D. C., Bandy, A. R., Tu, F. H., Blomquist, B. W., Mitchell, G. M., Nadler, W., and Lenschow, D. H.: Fast airborne sulfur dioxide measurements by Atmospheric Pressure Ionization Mass Spectrometry (APIMS), J. Geophys. Res.-Atmos., 107, 4632, doi:10.1029/2002JD002289, 2002.

Toniazzo, T., Abel, S. J., Wood, R., Mechoso, C. R., Allen, G., and Shaffrey, L. C.: Large-scale and synoptic meteorology in the south-east Pacific during the observations campaign VOCALSREx in austral Spring 2008, Atmos. Chem. Phys., 11, 49775009, doi:10.5194/acp-11-4977-2011, 2011.

Tsapakis, M., Lagoudaki, E., Stephanou, E. G., Kavouras, I. G., Koutrakis, P., Oyola, P., and von Baer, D.: The composition and sources of $\mathrm{PM}_{2.5}$ organic aerosol in two urban areas of Chile, Atmos. Environ., 36, 3851-3863, doi:10.1016/S13522310(02)00269-8, 2002.

Twohy, C. H., Anderson, J. R., Toohey, D. W., Andrejczuk, M., Adams, A., Lytle, M., George, R. C., Wood, R., Saide, P., Spak, S., Zuidema, P., and Leon, D.: Impacts of aerosol particles on the microphysical and radiative properties of stratocumulus clouds over the Southeast Pacific ocean, Atmos. Chem. Phys. Discuss., 12, 19715-19767, doi:10.5194/acpd-12-197152012, 2012.

Twomey, S.: Pollution and planetary albedo, Atmos. Environ., 8, 1251-1256, doi:10.1016/0004-6981(74)90004-3, 1974.

Wood, R.: Cancellation of aerosol indirect effects in marine stratocumulus through cloud thinning, J. Atmos. Sci., 64, 26572669, doi:10.1175/JAS3942.1, 2007

Wood, R., Johnson, D. W., Osborne, S. R., Andreae, M. O., Bandy, B., Bates, T. S., O'Dowd, C., Glantz, P., Noone, K.,Quinn, P. K., Rudolph, J., and Suhre, K.: Boundary layer and aerosol evolution during the third Lagrangian experiment of ACE-2, Tellus, 52B, 401-422, doi:10.1034/j.16000889.2000.00058.x, 2000.

Wood, R., Bretherton, C. S., Leon, D., Clarke, A. D., Zuidema, P., Allen, G., and Coe, H.: An aircraft case study of the spatial transition from closed to open mesoscale cellular convection over the Southeast Pacific, Atmos. Chem. Phys., 11, 2341-2370, doi:10.5194/acp-11-2341-2011, 2011a.

Wood, R., Mechoso, C. R., Bretherton, C. S., Weller, R. A., Huebert, B., Straneo, F., Albrecht, B. A., Coe, H., Allen, G., Vaughan, G., Daum, P., Fairall, C., Chand, D., Gallardo Klenner, L., Garreaud, R., Grados, C., Covert, D. S., Bates, T. S., Krejci, R., Russell, L. M., de Szoeke, S., Brewer, A., Yuter, S. E., Springston, S. R., Chaigneau, A., Toniazzo, T., Minnis, P., Palikonda, R., Abel, S. J., Brown, W. O. J., Williams, S., Fochesatto, J., Brioude, J., and Bower, K. N.: The VAMOS Ocean-Cloud-Atmosphere-Land Study Regional Experiment (VOCALS-REx): goals, platforms, and field operations, Atmos. Chem. Phys., 11, 627-654, doi:10.5194/acp-11-627-2011, 2011b. 
Woodhouse, M. T., Carslaw, K. S., Mann, G. W., Vallina, S. M., Vogt, M., Halloran, P. R., and Boucher, O.: Low sensitivity of cloud condensation nuclei to changes in the sea-air flux of dimethyl-sulphide, Atmos. Chem. Phys., 10, 7545-7559, doi:10.5194/acp-10-7545-2010, 2010.
Yang, Q., W. I. Gustafson Jr., Fast, J. D., Wang, H., Easter, R. C., Morrison, H., Lee, Y.-N., Chapman, E. G., Spak, S. N., and Mena-Carrasco, M. A.: Assessing regional scale predictions of aerosols, marine stratocumulus, and their interactions during VOCALS-REx using WRF-Chem, Atmos. Chem. Phys., 11, 11951-11975, doi:10.5194/acp-11-11951-2011, 2011. 